\title{
Hydrodechlorination of Trichloroethylene over Pd Supported on Swellable Organically-Modified Silica (SOMS)
}

\author{
Hyuntae Sohn ${ }^{1}$, Gokhan Celik ${ }^{1}$, Seval Gunduz ${ }^{1}$, Stacey L. Dean ${ }^{2}$, Eric Painting ${ }^{3}$. \\ Paul L. Edmiston ${ }^{2,3^{*}}$ and Umit S. Ozkan ${ }^{1 *}$
}

${ }^{1}$ William G. Lowrie Department of Chemical and Biomolecular Engineering, The Ohio State University, 151 W. Woodruff Avenue, Columbus, OH 43210, USA

${ }^{2}$ ABS Materials, Inc., 1909 Old Mansfield Road, Wooster, OH 44691, USA

${ }^{3}$ Department of Chemistry, The College of Wooster, 943 College Mall, Wooster, OH 44691, USA

*Corresponding Authors

Umit S. Ozkan

E-mail: ozkan.1@osu.edu

Tel: (614)-292-6623

Paul Edmiston

E-mail: pedmiston@wooster.edu

Tel: (330) 263-2113 


\begin{abstract}
The catalytic activity and resistance to poisoning of $\mathrm{Pd}$ catalysts supported on swellable organically-modified silica (SOMS) were investigated for hydrodechlorination (HDC) of trichloroethylene (TCE). The promising catalytic activity of $1 \% \mathrm{Pd} / \mathrm{SOMS}$ sample was attributed to the high affinity of SOMS for organics and its high hydrophobicity. While latter characteristic repels water, the adsorptive capacity for organics allows TCE dissolved in aqueous media to concentrate inside the pores, in the vicinity of the active sites, thus helping the kinetics. In the liquid phase, using a continuous flow reactor, higher TCE conversion was obtained over the $1 \%$ $\mathrm{Pd} / \mathrm{SOMS}$ compared to the commercial $1 \% \mathrm{Pd} / \mathrm{Al}_{2} \mathrm{O}_{3}$ catalyst. When the pores of $1 \% \mathrm{Pd} / \mathrm{SOMS}$ sample were fully opened by pre-treating it with ethanol prior to the reaction, HDC activity was seen to significantly increase. In the gas phase, the extent of adsorption was less, reducing the concentration of reactants near the active sites. As a result, $1 \% \mathrm{Pd} / \mathrm{SOMS}$ was less active than $1 \%$ $\mathrm{Pd} / \mathrm{Al}_{2} \mathrm{O}_{3}$ for $\mathrm{HDC}$ of TCE. To determine their resistance to poisoning, $1 \% \mathrm{Pd} / \mathrm{SOMS}$ and $1 \%$ $\mathrm{Pd} / \mathrm{Al}_{2} \mathrm{O}_{3}$ catalysts were poisoned ex-situ with $\mathrm{Li}_{2} \mathrm{~S}$. The ex-situ poisoned $\mathrm{Pd} / \mathrm{SOMS}$ sample maintained its catalytic activity for HDC of TCE. However, a significant loss in catalytic activity of the $\mathrm{Pd} / \mathrm{Al}_{2} \mathrm{O}_{3}$ catalyst was observed after poisoning. Protection from aqueous phase sulfide poisoning was attributed to the hydrophobicity of the Pd/SOMS, which would exclude anionic species from the embedded Pd particles. The XPS, STEM and ICP-OES results indicated that when $\mathrm{Pd} / \mathrm{Al}_{2} \mathrm{O}_{3}$ and $\mathrm{Pd} / \mathrm{SOMS}$ were treated with $1 \mathrm{M} \mathrm{HCl}$, most of the $\mathrm{Pd}$ metal was leached from the $\mathrm{Pd} / \mathrm{Al}_{2} \mathrm{O}_{3}$ catalyst in contrast to $\mathrm{Pd} / \mathrm{SOMS}$, which had negligible leaching. Overall, due to hydrophobicity and high affinity for organics, SOMS has potential as a catalyst scaffold for different reactions in groundwater remediation applications.
\end{abstract}

KEYWORDS: SOMS; organosilica; hydrodechlorination; trichloroethylene; palladium 


\section{Introduction}

Contamination of groundwater continues to attract public attention due to its importance as a source of drinking water. Trichloroethylene (TCE), which has been extensively used as a metal degreaser [1], is one of the most widely detected volatile organic compound (VOC) contaminants in groundwater $[2,3]$. The high level of toxicity and the carcinogenic effects of TCE pose a serious threat to the environment and human health [4]. The current groundwater remediation technologies for removal of TCE are mostly based on adsorption and extraction techniques that require further treatment $[5,6]$. Therefore, using catalytic processes for TCE remediation, which result in the complete destruction of its chemical structure has many advantages.

Hydrodechlorination (HDC) of TCE is a catalytic reaction where hydrogen is used as a reducing agent to remove chlorine, producing ethane and hydrochloric acid $(\mathrm{HCl})$ as the major products. Among many different precious metals that are used for this process, Pd-based catalysts have exhibited promising catalytic activity for HDC of TCE, especially on alumina or activated carbon (AC) supports [7-12]. Lowry et al. conducted HDC of TCE experiments in liquid phase on $1 \% \mathrm{Pd} / \mathrm{Al}_{2} \mathrm{O}_{3}$ and metallic $\mathrm{Pd}$ powders. The highest TCE conversion they achieved was $97 \%$ for $\mathrm{Pd} / \mathrm{Al}_{2} \mathrm{O}_{3}$, with no by-products observed at room temperature and atmospheric pressure [7]. The Pd particle size was also reported to impact the catalytic activity. Zhang and co-workers showed that CMC (carboxymethyl cellulose)-stabilized Pd nanoparticles over $\mathrm{Al}_{2} \mathrm{O}_{3}$ was much more active than the commercial $\mathrm{Pd} / \mathrm{Al}_{2} \mathrm{O}_{3}$ for liquid phase $\mathrm{HDC}$ of TCE [11]. Bimetallic catalysts such as $\mathrm{Ni} / \mathrm{Fe}$ [13], $\mathrm{Pd} / \mathrm{Sn}$ [14], $\mathrm{Pd} / \mathrm{NiMgAl}$ [15], $\mathrm{PdCu}$ alloy [16] and $\mathrm{Pt}$ and $\mathrm{Pd}$ containing $\mathrm{Cu}$-hydrotalcite [17] have also been studied for this reaction. Meshesha et al. have observed close to $100 \%$ ethylene selectivity at $300^{\circ} \mathrm{C}$ using $\mathrm{PdCu}$ alloy nanoparticles supported over $\mathrm{Al}_{2} \mathrm{O}_{3}$ [16]. The highest TCE hydrodechlorination rate in the literature was reported by Wong and co-workers using bimetallic $\mathrm{Pd} / \mathrm{Au}$ nanoparticles $[18,19]$. The authors conducted a comparison study over $\mathrm{Pd}$ black powders, $\mathrm{Pd} / \mathrm{Al}_{2} \mathrm{O}_{3}, \mathrm{Pd}$ nanoparticles, $\mathrm{Pd} / \mathrm{Au}$ nanoparticles, $\mathrm{Au} / \mathrm{Al}_{2} \mathrm{O}_{3}, \mathrm{Au} / \mathrm{Pd} / \mathrm{Al}_{2} \mathrm{O}_{3}$ and $\mathrm{Pd} / \mathrm{Au} / \mathrm{Al}_{2} \mathrm{O}_{3}$ in terms of their overall catalytic activity. The results exhibited that $\mathrm{Pd} / \mathrm{Au}$ nanoparticles were significantly more active than other catalysts in aqueous phase for HDC of TCE with a rate constant that was 70 times higher than the commercially available $\mathrm{Pd} / \mathrm{Al}_{2} \mathrm{O}_{3}$ catalysts on per $\mathrm{Pd}$ atom basis. Several additional techniques have been proposed to make the HDC process more economical. One of the more recent methods is the 
microwave heating that has been presented as an alternative way to heat the reactor up to the desired reaction temperature of TCE HDC [20, 21]. In addition, alternative organic hydrogen donors have been explored such as 2-propanol [22] and formic acid [23, 24] in liquid phase HDC reactions.

Although Pd-based catalysts have exhibited very good catalytic performance, catalyst deactivation due to ionic poisons dissolved in groundwater is still a recurring issue. For instance, formation of metal- $\mathrm{Cl}$ bonds due to chloride ions $\left(\mathrm{Cl}^{-}\right)$in groundwater as well as from the reaction itself has been found to diminish the catalytic performance in hydrodechlorination reactions [17, 25-28]. Furthermore, sulfur-containing anions [29] such as sulfate $\left(\mathrm{SO}_{4}{ }^{2-}\right)$ and bisulfide $\left(\mathrm{HS}^{-}\right)$, and bicarbonate $\left(\mathrm{HCO}^{3-}\right)$ [30] are also poisoning sources which degrade the catalysts.

With respect to chloride poisoning, Ordóñez et al. suggested that the more acidic the support is, the more the affinity it has towards chloride ions [25]. Although the oxidation of metallic Pd under a $\mathrm{H}_{2}$ environment is not thermodynamically favorable, the presence of chloride ions stabilizes $\mathrm{Pd}$ in an oxidized state by forming different complexes, such as $\mathrm{PdCl}_{3}{ }^{-}$and $\mathrm{PdCl}_{4}{ }^{2-}$, thus decreasing the catalyst performance drastically. Their results indicated that $\mathrm{Pd} / \mathrm{Al}_{2} \mathrm{O}_{3}$, which is more acidic, showed faster deactivation than Pd/AC for TCE HDC. Moreover, in order to minimize the contact between Pd metal and ionic poisons such as sulfide-containing species, coating materials such as poly-dimethylsiloxane (PDMS) have been tested for HDC reactions [31, 32]. This is to enhance the hydrophobicity of the catalysts thereby repelling ionic poisons dissolved in groundwater. However, an associated issue was that $\mathrm{HCl}$ produced from the HDC reaction degraded the polymers.

In this study, we attempted to increase the hydrophobicity of the matrix surrounding Pd using a swellable organically-modified silica (SOMS) material as a catalyst scaffold [33-35]. SOMS is extremely hydrophobic and can adsorb a variety of organic molecules including TCE [35]. Another interesting aspect of SOMS is that it consists a crosslinked organosilica network with flexible linkages, thereby allowing a physical volume expansion of the material (swelling). While swelling, it is known to create extra surface area and micropores. The swelling process is reversible through evaporation, in which the volume of the SOMS returns to its original state. 
Pd supported on SOMS catalyst has never been investigated for its catalytic activity for HDC of TCE. Therefore, in the present paper, the TCE reaction over the Pd/SOMS catalyst was studied used a continuous flow reactor system both in the liquid and the gas phase. Poisoning and leaching studies were also conducted using $\mathrm{Li}_{2} \mathrm{~S}$ and $\mathrm{HCl}$, respectively. The catalytic performance of the samples treated with $\mathrm{Li}_{2} \mathrm{~S}$ and $\mathrm{HCl}$ were compared to fresh $\mathrm{Pd} / \mathrm{SOMS}$ catalysts as well as to commercial $\mathrm{Pd} / \mathrm{Al}_{2} \mathrm{O}_{3}$ catalyst, which was used as a reference. The HCltreated $\mathrm{Pd} / \mathrm{SOMS}$ and $\mathrm{Pd} / \mathrm{Al}_{2} \mathrm{O}_{3}$ catalysts were characterized by X-ray photoelectron spectroscopy (XPS) and high angle annular dark field (HAADF) scanning transmission electron microscopy (STEM). Inductively coupled plasma optical emission spectrometry (ICP-OES) technique was used measure the extent of Pd leaching of the catalysts. Lastly, the chemical structure, thermal stability, extent of hydrophobicity, surface area and pore volume were examined using RAMAN and Infrared (IR) spectroscopy, temperature programmed oxidation (TPO), thermo-gravimetric analysis (TGA), and $\mathrm{N}_{2}$ physisorption techniques.

\section{Experimental}

\subsection{Catalyst Preparation}

The synthesis procedure for SOMS was reported previously by Edmiston and co-workers [33-37]. In brief, it involves a sol-gel synthesis consisting of polycondensation of an aromatically bridged silane precursor (monomer) with flexible linkages between the aryl group and the silicon centers (e.g., [bis(trimethoxysilylethyl) benzene (BTEB) shown in Figure 1), followed by hydrolysis and condensation reactions initiated by fluoride ion (e.g., tetrabutyl ammonium fluoride) as a catalyst (leading to Si-O-Si bond formation). Organization of the polycondensed BTEB is aided by $\pi-\pi$ stacking interactions of the aryl rings. After aging the gel for 6 days, residual silanol groups are derivatized by end-capping them with organic functional groups (e.g., trimethylchlorosilane $\left.\left(\mathrm{Si}\left(\mathrm{CH}_{3}\right)_{3} \mathrm{Cl}\right)\right)$ which prevents $\mathrm{Si}-\mathrm{O}-\mathrm{Si}$ bond formation during drying, preserving flexibility in the matrix. The crucial step in the synthesis is the choice of the monomer since swelling behavior is observed only when flexible linkages between the aryl group and the silicon centers exist.

$1 \%$ w/w Pd/SOMS was prepared using Pd(II) acetate (Sigma-Aldrich 98\%) through incipient wetness impregnation (IWI) technique. The Pd acetate was first dissolved in acetone and stirred 
rigorously to obtain a homogenous Pd precursor solution. The mixture was then added to the SOMS support drop-wise using a micropipette at which point the volume of SOMS expanded (swelled). Once the expansion was reached a maximum state, SOMS was dried at $25^{\circ} \mathrm{C}$ with constant agitation. The swelling and drying process was repeated until all the precursor solution was added to the SOMS support. $\mathrm{Pd}^{2+}$ was reduced by swelling the material with a saturated solution of $\mathrm{NaBH}_{4}$ in $95 \%$ ethanol. The $\mathrm{Pd} / \mathrm{SOMS}$ particles were then filtered and extensively rinsed with ethanol and then with deionized water, and dried at $60^{\circ} \mathrm{C}$. The particle size was of the $\mathrm{Pd} / \mathrm{SOMS}$ was $\sim 150 \mu \mathrm{m}$.

Commercial $1 \% \mathrm{Pd} / \mathrm{Al}_{2} \mathrm{O}_{3}$ was purchased from Sigma-Aldrich. The $1 \% \mathrm{Pd} / \mathrm{Al}_{2} \mathrm{O}_{3}$ was reduced using $5 \% \mathrm{H}_{2} / \mathrm{He}$ gas at $400{ }^{\circ} \mathrm{C}$ for $1 \mathrm{~h}$. The reduction was carried out either ex-situ or in-situ for liquid phase and gas phase reactions, respectively. To desorb any species that may be adsorbed from the atmosphere, the sample was first treated with helium at $450{ }^{\circ} \mathrm{C}$ for $30 \mathrm{~min}$.

\subsection{Catalyst Characterization}

\subsubsection{Raman and Infrared (IR) Spectroscopy}

Raman spectra were collected with a Renishaw-Smiths Detection Combined Raman-IR Microprobe equipped with Leica and CCD detector (400 X 576). SOMS material was placed on a stainless steel sample holder where a helium-neon laser $(633 \mathrm{~nm})$ beam was focused on a particular spot (x20 objective). The spectra were collected using an exposure time of $50 \mathrm{~s}^{-1}$ in the $300-4000 \mathrm{~cm}^{-1}$ range. FT-IR-ATR spectra were measured using a Thermo Nicolet 6700 FTIR Spectrometer with a diamond attenuated total reflectance accessory.

\subsubsection{Temperature Programmed Oxidation (TPO)}

SOMS was placed in a $4 \mathrm{~mm}$-ID quartz reactor, which was then loaded into a Carbolite MTF $10 / 15 / 130$ furnace. A gas mixture of $5 \% \mathrm{O}_{2} / \mathrm{He}$ was introduced to the reactor at $30 \mathrm{ml} / \mathrm{min}$ at RT and the outlet stream was connected to a mass spectrometer (MKS-Cirrus II) operated in scanning ion mode. The signals from $m / z=2$ to 60 were all monitored in order to detect various 
products. TPO was performed using a $10{ }^{\circ} \mathrm{C} / \mathrm{min}$ temperature ramp rate at which the temperature was increased from RT to $800^{\circ} \mathrm{C}$.

\subsubsection{Surface Area, Pore Size and Pore Volume}

Micromeritics ASAP 2020 (accelerated surface area and porosimetry) instrument was used to obtain nitrogen adsorption/desorption isotherms of the SOMS, $1 \% \mathrm{Pd} / \mathrm{SOMS}$ and $1 \% \mathrm{Pd} / \mathrm{Al}_{2} \mathrm{O}_{3}$ catalysts. First, the sample was degassed for $12 \mathrm{~h}$ at $130{ }^{\circ} \mathrm{C}$ under $2 \mu \mathrm{m} \mathrm{Hg}$ of vacuum in order to remove any gas molecules captured inside the pores and impurities on the surface. The degassed sample was then transferred to the analysis port where the nitrogen adsorption took place at liquid nitrogen temperature. The collected isotherms were used to calculate the BrunauerEmmett-Teller (BET) surface area and Brunauer-Joyner-Helena (BJH) pore volumes of the samples. The pore size distribution was obtained from the desorption curve of the isotherm.

\subsubsection{High Angle Annular Dark Field (HAADF) Scanning Transmission Electron Microscopy (STEM) and Energy-Dispersive X-ray Analysis (EDAX)}

HADDF-STEM images were taken by FEI Tecnai F20 instrument equipped with a high brightness field emission electron gun (FEG) operated at $200 \mathrm{kV}$ and a HADDF detector. Prior to the imaging, the $\mathrm{Pd} / \mathrm{SOMS}$ and $\mathrm{Pd} / \mathrm{Al}_{2} \mathrm{O}_{3}$ samples were suspended in ethanol and sonicated for 5 min. After obtaining a homogeneous mixture a drop of it was added on a Tedpella, Inc. 200 mesh copper grid sample holder, which was coated with lacey carbon. For identification of Pd particles, EDAX spectra were collected over all the samples.

\subsubsection{Static Vapor-Phase Adsorption}

Static vapor equilibrium adsorption at $25^{\circ} \mathrm{C}$ were measured over time using Pyris 1 Perkin-Elmer thermo-gravimetric analyzer. A mass of sample was placed on the balance and a neat liquid or solid was added to the sealed analysis chamber to yield a static condition of saturated vapor. Mass was measured every $6 \mathrm{~s}$ until equilibrium was reached. 


\subsection{6. in situ Diffuse Reflectance Infrared Fourier Transform Spectroscopy}

(DRIFTS)

In situ DRIFTS experiments during temperature programmed desorption (TPD) was performed using a Thermo NICOLET 6700 FTIR spectrometer. The instrument includes a MCT detector operating at liquid nitrogen temperature and a $\mathrm{KBr}$ beam splitter. In situ experiments were conducted in a Praying Mantis controlled atmosphere reaction chamber in which the samples were loaded. A TCE bubbler at room temperature was used to generate TCE vapors, which were then introduced to the reactor cell using helium as a balance gas. After $1 \mathrm{hr}$ of TCE adsorption, the reaction chamber was flushed with helium for $5 \mathrm{~min}$ and a spectrum was collected at $25{ }^{\circ} \mathrm{C}$. The temperature was then increased to the next desired set point and another spectrum was collected. The process was repeated up to a temperature of $250{ }^{\circ} \mathrm{C}$.

\subsubsection{X-ray Photoelectron Spectroscopy (XPS)}

XPS spectra were collected over the $\mathrm{Pd} / \mathrm{SOMS}$ and $\mathrm{Pd} / \mathrm{Al}_{2} \mathrm{O}_{3}$ catalysts by using a Kratos AXIS Ultra X-ray photoelectron spectrometer with a monochromatized $\mathrm{Al} \mathrm{K}_{\alpha} \mathrm{X}$-ray source operated at $13 \mathrm{kV}$ and $10 \mathrm{~mA}$. The sample was loaded in the chamber using carbon tape and was evacuated overnight. For each sample, a survey scan was taken in order to identify all the elements present on the catalyst surface. After the survey scan, spectra for the specific C 1s, O 1s, Cl 2p, Pd 3d and Si $2 p$ regions were collected. Prior to the data analysis, the charging effect was corrected based on the $\mathrm{C} 1 \mathrm{~s}$ binding energy of $284.5 \mathrm{eV}$. The background subtraction, normalization and peak fitting of the data were performed in CasaXPS software.

\subsubsection{Inductively Coupled Plasma Optical Emission Spectrometry (ICP-OES)}

To examine leaching characteristics of the active metal in pre-reduced $1 \% \mathrm{Pd} / \mathrm{Al}_{2} \mathrm{O}_{3}$ and $1 \%$ $\mathrm{Pd} / \mathrm{SOMS}$, samples $1 \mathrm{M} \mathrm{HCl}$ poisoning was conducted by stirring each of the two samples in 40 $\mathrm{ml}$ of $0,0.1$ and $1 \mathrm{M} \mathrm{HCl}$ solutions for $20 \mathrm{~min}$ at RT. The resulting mixture was then filtered to 
remove all the residual solids. The elemental analysis of $\mathrm{Pd}$ in the $\mathrm{HCl}$ solution was conducted utilizing a Perkin-Elmer Optima 4300DV ICP-OES.

\subsection{Catalytic Activity Testing}

\subsubsection{HDC of TCE in the Liquid Phase}

A continuous flow, fixed bed reactor was constructed using a LCC-500 fast flow liquid chromatography system (Pharmacia). A diagram of the reactor system is shown in Figure 2. All the experiments were based on equal liquid hour space velocity (LHSV = reactant flow rate/reactor volume). The liquid feed consisted of water, TCE, $\mathrm{H}_{2}$ and methanol. Deionized water was saturated with $\mathrm{H}_{2}$ by continuously sparging the $4 \mathrm{~L}$ source water reservoir. TCE was dissolved in methanol $(5.18 \mathrm{mg} / \mathrm{mL})$, to allow rapid dissolution, and introduced to the flow stream by a syringe pump. TCE solution feed rates were either $2.4 \mathrm{~mL} / \mathrm{hr}$ when TCE was limiting or $9.6 \mathrm{~mL} / \mathrm{hr}$ when the dissolved $\mathrm{H}_{2}$ was the limiting reagent. A $50-60 \mathrm{~Hz}$ mixer upstream of the catalyst bed ensured a homogenous solution. Catalyst was added to a $15 \mathrm{~mm}$ diameter water-jacketed chromatography column (GE-Pharmacia) so that the bed thickness remained constant at $4 \mathrm{~mm}$ which required $2.0 \mathrm{~g}$ of $\mathrm{Pd} / \mathrm{Al}_{2} \mathrm{O}_{3}, 0.40 \mathrm{~g}$ of $\mathrm{Pd} / \mathrm{SOMS}$, and $0.27 \mathrm{~g}$ of pre-swollen Pd/SOMS. Catalyst bed was maintained at $30{ }^{\circ} \mathrm{C}$. Flow rate was $20 \mathrm{~mL} / \mathrm{min}(\sim 40$ bed volumes per min).

Reaction progress was monitored by measuring the conductivity of the water in the effluent of the catalytic bed ( $\mathrm{HCl}$ production) using a Pharmacia Biotech 18-1500 conductivity monitor with $1 \mathrm{~Hz}$ data acquisition. In addition, a sampling port was used to collect product stream samples into sealed vials for analysis of chlorinated solvents by headspace gas chromatography-mass spectrometry (GC-MS) using an 6980/5973 instrument (Agilent).

\subsubsection{HDC of TCE in the Gas Phase}

The catalytic activity of the $1 \% \mathrm{Pd} / \mathrm{SOMS}$ and $1 \% \mathrm{Pd} / \mathrm{Al}_{2} \mathrm{O}_{3}$ in the gas phase for HDC of TCE was measured using a bench-scale fixed-bed flow reactor system. The catalyst was first placed inside a 4 mm-ID quartz reactor using quartz wool plugs to support the catalyst bed. The reactor 
was then positioned in the center of a furnace (Carbolite, MTF 10/15/130) whose temperature was adjusted by an Omega CSC232 PID temperature controller. The outlet of the reactor was connected to an online gas chromatographer (Shimadzu Scientific 2010) equipped with a Q-bond column and a flame ionization detector (FID) for separation, identification, and quantification of all the products. The inlet stream to the reactor contained $0.7 \%$ TCE, excess hydrogen $(1: 30$, TCE-to-hydrogen molar ratio), and nitrogen as the balance gas. The TCE vapors were generated by using a stainless-steel bubbler, which contained pure TCE and which was hold at $35^{\circ} \mathrm{C}$ using nitrogen as a carrier gas. The effluent gas mixture from the bubbler was then mixed with additional nitrogen and excess hydrogen to obtain $0.7 \%$ TCE in feed stream. In order to investigate the effect of water on the catalytic activity of the samples, water was added to the reactant stream. Similar to the TCE, a water bubbler, which was maintained at $35{ }^{\circ} \mathrm{C}$, was to generate water vapor. The total water concentration used in the feed stream was 4\%. The HDC of TCE reaction was performed at $50{ }^{\circ} \mathrm{C}, 100{ }^{\circ} \mathrm{C}, 150{ }^{\circ} \mathrm{C}$ and $200{ }^{\circ} \mathrm{C}$.

All the gas lines (Swagelok) were held at temperatures above $200{ }^{\circ} \mathrm{C}$ to prevent any condensation of the reactants and products. Prior to the HDC reaction experiment, the $1 \%$ $\mathrm{Pd} / \mathrm{Al}_{2} \mathrm{O}_{3}$ was pre-reduced in-situ by using $5 \% \mathrm{H}_{2} / \mathrm{He}$ at $400^{\circ} \mathrm{C}$ for $1 \mathrm{~h}$. The $\mathrm{Pd} / \mathrm{SOMS}$ was chemically reduced using $\mathrm{NaBH}_{4}$. The quantification of the products and reactants was done based on calibration curves that were obtained periodically. The catalytic activity comparison between the two samples was based on equal gas hour space velocity (GHSV).

\section{Results and Discussion}

\subsection{Structure of SOMS}

SOMS is synthesized using a bis(trimethoxysilylethyl)benzene (BTEB) silane monomer precursor which contains a benzene ring directly connected to silicon (Figure 1). The polycondensation of BTEB during sol-gel synthesis creates a highly cross-linked polymer matrix including covalent linkages between the aryl group and silicon. In a recent study, Edmiston and co-workers [33, 34] have examined the effect of various parameters such as the choice of precursor, solvent, catalysts, aging time and silane concentration to investigate the principle behind the swelling behavior. Interestingly, the swelling behavior of SOMS was only obtained 
by the two precursors that included a covalent bond between the aryl groups connected to the silicon center. Thus, the flexibility of SOMS is possibly correlated to the Si-C-aryl bonds. To obtain a better understanding of the chemical structure of SOMS, two different spectroscopy techniques were used.

\subsubsection{Raman Spectroscopy}

Raman spectrum was collected over the bare SOMS support. Figure 3 (a) shows the spectrum region of $300-1800 \mathrm{~cm}^{-1}$. The band with the strongest intensity at $1000 \mathrm{~cm}^{-1}$ is attributed to mono, 1,3 and 1,3,5 substituted benzenes [38]. This indicates that the aromatic ring originating from the BTEB precursor was stable throughout the synthesis process. The Si-O-Si asymmetric stretching was observed as a sharp feature at $1079 \mathrm{~cm}^{-1}[39,40]$ whereas the Si-O-Si symmetric stretching was assigned to a peak at $640 \mathrm{~cm}^{-1}$ [41, 42]. Several other peaks appeared around the lower wavelength region below $1000 \mathrm{~cm}^{-1}$. The bands at 484 and $603 \mathrm{~cm}^{-1}$ are possibly related to threeor four-membered rings of the Si-O-Si symmetric stretching mode, which are typically found in silica Raman spectra [43, 44]. However, the intensity of these peaks were much lower. The features for $\mathrm{Si}_{-} \mathrm{CH}_{3}$ appear as a sharp peak at $1240 \mathrm{~cm}^{-1}$ ascribed to the $\mathrm{CH}_{3}$ symmetric deformation [40]. Peaks at 812 and $842 \mathrm{~cm}^{-1}$ were associated to two methyl groups in $\mathrm{Si}-\left(\mathrm{CH}_{3}\right)_{2}$ binding to the silicon center and the band at $1412 \mathrm{~cm}^{-1}$ was attributed to the asymmetric stretching of the $\mathrm{CH}_{3}$ species [40]. It is likely that $\mathrm{Si}_{-} \mathrm{CH}_{2}-\mathrm{R}$ bonds are present in the structure. The 692 and $743 \mathrm{~cm}^{-1}$ bands were assigned to the rocking vibration of $\mathrm{CH}_{2}$ [40]. Si-O-CH3 bonds were also identified as a strong peak at $1181 \mathrm{~cm}^{-1}$ [40]. The $\mathrm{CH}_{3}$ symmetric stretching in $\mathrm{C}-\mathrm{CH}_{3}$ group were also seen at $1334 \mathrm{~cm}^{-1}$ [40]. The higher wavenumber range above $1400 \mathrm{~cm}^{-1}$ are mostly due to adsorption of aromatic groups. The 1452, 1588 and $1606 \mathrm{~cm}^{-1}$ peaks are due to aromatic rings with different substituents $[40,45]$.

The high wavenumber-region of the spectrum led to similar observations as seen in Figure 3 (b). The adsorption due to $\mathrm{C}-\mathrm{H}$ stretching in aromatic rings were observed at 3004 and $3057 \mathrm{~cm}^{-1}$ [40, 45]. The peaks at 2956, 2901 and $2876 \mathrm{~cm}^{-1}$ are attributed to $\mathrm{C}-\mathrm{H}$ vibration in $\mathrm{CH}_{3}$ or $\mathrm{CH}_{2}$ groups of aliphatic compounds [40, 45], or $\mathrm{Si}-\mathrm{O}-\mathrm{CH}_{3}$ groups [46]. 


\subsubsection{IR Spectroscopy}

The structural characteristics of the SOMS materials were also examined using IR spectroscopy (Figure 4). The two overlapping peaks at 1034 and $1093 \mathrm{~cm}^{-1}$ indicate Si-O-Si stretching [47]. The shoulder of Si-O-Si band is characteristic of SOMS and due to longitudinal-optic (LO)transverse-optical (TO) splitting of the vibrational modes. LO-TO splitting has been attributed to long range coupling of Coulomb interactions [48-50]. Specifically, the antisymmetric stretching $\mathrm{LO}_{3}(1188)-\mathrm{TO}_{3}(1093) \mathrm{cm}^{-1}$ bands observed in SOMS are likely explained as scattering in larger pore structures [51].

The Si-OH groups were not observed, i.e. showing no notable peaks around the $3000-3600 \mathrm{~cm}^{-1}$ or $950 \mathrm{~cm}^{-1}$ regions [47]. This is due to the $\mathrm{Si}-\mathrm{OH}$ groups being capped by treatment with chlorotrimethysilane in the synthesis of SOMS [33] leading to O-Si- $\left(\mathrm{CH}_{3}\right)_{3}$ groups which were detected by Raman and observed in the IR by three distinctive peaks at 764, 845 and $1252 \mathrm{~cm}^{-1}$ [47]. Multiple bands associated with the aromatic ring were shown in the spectrum. Two strong peaks at 688 and $754 \mathrm{~cm}^{-1}$ exhibit features that correspond to out-of-plane C-H bending or wagging vibrations of mono and meta substituted benzenes [47, 52]. The in-plane $\mathrm{C}-\mathrm{H}$ bending was observed around 1400-1700 $\mathrm{cm}^{-1}$ region. The five peaks at 1406, 1448, 1489, 1512, and $1606 \mathrm{~cm}^{-1}$ can be related to a combination of mono, ortho, meta and para substituted benzenes of the SOMS structure [52].

\subsection{Thermal Stability of SOMS}

SOMS is an organosilica-based material which consists of a crosslinked network. It is expected that under extreme thermal treatment, the structure of SOMS collapses due to decomposition of the organic groups, resulting in the loss of the swelling capability and hydrophobicity. Hence, a TPO experiment was conducted to determine an accurate decomposition temperature of the SOMS material. As shown in Figure 5, a significant oxygen consumption feature was observed around $500{ }^{\circ} \mathrm{C}$, simultaneously producing a large amount of $\mathrm{CO}_{2}$. This clearly shows that the decomposition of SOMS with $\mathrm{C}-\mathrm{C}$ bond cleavage. Some amount of $\mathrm{H}_{2} \mathrm{O}$ and $\mathrm{CH}_{4}$ was also detected as products. Interestingly, the swelling property and hydrophobicity in the post-TPO SOMS sample was still present (data not shown). However, the degree of physical volume 
expansion was significantly reduced compared to the fresh SOMS support. The weak thermal stability of the SOMS support limited its utilization in the $\mathrm{H}_{2}$ pre-reduction process, which requires high temperatures. Thus, for this study, all of the Pd/SOMS samples were pre-reduced using $\mathrm{NaBH}_{4}$ at room temperature.

\subsection{Surface Area, Pore Size and Pore Volume}

The nitrogen isotherms of the samples were collected using an ASAP 2020 instrument to obtain BET surface area, BJH pore volume and averaged pore diameter. The calculated values are shown in Table 1. The impregnation of Pd on the SOMS support showed reduction in surface area, pore volume and averaged pore diameter. This is likely attributed to the filling/blockage of the pores of the SOMS support by Pd particles. The surface area of 1\% Pd/SOMS was higher than that of the $1 \% \mathrm{Pd} / \mathrm{Al}_{2} \mathrm{O}_{3}$ commercial catalyst. However, $1 \% \mathrm{Pd} / \mathrm{Al}_{2} \mathrm{O}_{3}$ exhibited a higher pore volume and a higher average pore. The BJH pore size distributions are shown in Figure 6. As it can be seen, a significant decrease in number of pores of 50-200 A over the SOMS support was observed after the Pd impregnation process. For Pd/SOMS sample, most of the pores detected were close to $50 \AA$ (mesopores) whereas a wide pore size distribution in the range of 50-400 ̊ was obtained for $\mathrm{Pd} / \mathrm{Al}_{2} \mathrm{O}_{3}$.

All the SOMS and 1\% Pd/SOMS samples tested here were in their closed state, i.e., before any physical expansion of the material has taken place. The open-state of these samples were not subjected for the analysis due to the degassing and analysis conditions. However, it should be noted that the surface area and pore volume of the open-SOMS and open-1\% Pd/SOMS are expected to be significantly greater compared to the closed state of the two samples. This is attributed to the generation of the inner surface area during swelling of the samples, hence, the actual surface area, pore volume and pore size would be higher under reaction conditions.

\subsection{Hydrophobicity and Adsorption Capacity of $1 \% \mathrm{Pd} / \mathrm{SOMS}$ vs $1 \% \mathrm{Pd} / \mathrm{Al}_{2} \mathrm{O}_{3}$}

Adsorption capacity of SOMS for different organics (acetone, heptane, methanol, TCE, and benzene) was measured at room temperature using the static vapor adsorption technique and 
compared to that for water vapor. The term adsorption here refers to physisorption and involves pore filling. The mass intake profiles for these organics and for water are shown in Figure 7. The results indicate SOMS had adsorptive capacity for organic vapors between $60-100 \%$ w/w. Capacity after $120 \mathrm{~min}$ exposure time was generally non-selective across all organic vapors. In contrast, water vapor adsorption was $<7 \% \mathrm{w} / \mathrm{w}$, verifying the high hydrophobicity of SOMS.

In an earlier study by Edmiston and co-workers [35], SOMS was shown to be capable of adsorbing both polar and non-polar organic substances dissolved in aqueous phase. The study reported adsorption capacity for several organics, including PCE, TCE, toluene, methyl t-butyl ether (MTBE), acetone, naphthalene, and 1-butanol. Especially several compounds that are very relevant to water contamination problem such as PCE, TCE and toluene were adsorbed from water by SOMS at extraction levels of $92 \%$ or above [35].

Figure 7 (b) shows a comparison of $1 \% \quad \mathrm{Pd} / \mathrm{SOMS}$ and $1 \% \quad \mathrm{Pd} / \mathrm{Al}_{2} \mathrm{O}_{3}$ catalysts and their adsorption uptake capacities for gas-phase acetone and water. The adsorption selectivity of acetone to water, i.e., ratio of the weight of acetone adsorbed to that of water adsorbed, was seen to be much higher for $\mathrm{Pd} / \mathrm{SOMS}$ than it was for $\mathrm{Pd} / \mathrm{Al}_{2} \mathrm{O}_{3}$ as seen in the inset. It also shows that SOMS is much more hydrophobic than $\mathrm{Al}_{2} \mathrm{O}_{3}$ and the $\mathrm{Pd}$ impregnation of the reduction step with $\mathrm{NaBH}_{4}$ does not change the hydrophobic nature of this material.

\subsection{HDC of TCE in Liquid Phase}

\subsection{1 $\mathrm{Pd} / \mathrm{SOMS}$ vs. $\mathrm{Pd} / \mathrm{Al}_{2} \mathrm{O}_{3}$}

The catalytic activity of $\mathrm{Pd} / \mathrm{SOMS}$ and $\mathrm{Pd} / \mathrm{Al}_{2} \mathrm{O}_{3}$ was investigated in liquid phase for $\mathrm{HDC}$ of TCE using a continuous flow reactor system where the aqueous phase reactant mixture (TCE + water), was introduced into a fixed catalyst bed. A thin bed of supported catalyst was used to give a short residence time to better assess the kinetics of the HDC reaction. The effluent stream from the reactor was monitored by a conductivity detector, where the concentration of $\mathrm{HCl}$ was directly correlated to hydrodechlorination activity of the catalyst. These experiments were conducted in three parts: (i) with $180 \mu \mathrm{M}$ TCE (24 ppm) in the feed, i.e., TCE is the limiting reactant; (ii) with $320 \mu \mathrm{M}$ TCE (42 ppm) in the feed, i.e., $\mathrm{H}_{2}$ is the limiting reactant; (iii) ending 
with TCE-free feed. In all three parts of the experiment, $\mathrm{H}_{2}$ concentration in the feed was kept constant at $775 \mu \mathrm{M}$.

Figure 8 (a) shows the liquid-phase hydrodechlorination of TCE over $1 \% \quad \mathrm{Pd} / \mathrm{Al}_{2} \mathrm{O}_{3}$ at three different TCE concentrations. The green bar at the top of each section indicates the theoretical $\mathrm{HCl}$ concentration when complete hydrodechlorination of TCE is achieved. When $180 \mu \mathrm{M}$ of TCE was introduced to the reactor, after a transient period of $290 \mathrm{~s}$, a steady-state percent hydrodechlorination (\%HDC) of around $35 \%$ was obtained over the $1 \% \mathrm{Pd} / \mathrm{Al}_{2} \mathrm{O}_{3}$ catalyst. Here $\% \mathrm{HDC}$ is defined as $100 \times($ moles of $\mathrm{HCl}$ produced $) /(3 \times$ moles of TCE fed). The $\% \mathrm{HDC}$ slightly increased to $40 \%$ as TCE concentration was increased to $320 \mu \mathrm{M}$. As expected, when there was no TCE in the reactor feed, as shown in the third section of the graph, the $\mathrm{HCl}$ concentration in the effluent quickly dropped to $0 \mu \mathrm{M}$. Water collected during the steady-state period $(t=1,200 \mathrm{~s})$ was tested for the presence of chlorinated solvents by GC-MS. At steady state, TCE $\left(C_{\mathrm{out}} / C_{\mathrm{in}}=0.25\right)$, and a range of partially dechlorinated compounds including dichloroethylene, and vinyl chloride were detected in the effluent, supporting incomplete HDC reaction as indicated by sub-stoichiometric $\mathrm{HCl}$ production.

$\mathrm{Pd} / \mathrm{SOMS}$ catalyst showed a different performance from $\mathrm{Pd} / \mathrm{Al}_{2} \mathrm{O}_{3}$ (Fig 8 (b)). For Pd/SOMS, the transient period was much longer ( $850 \mathrm{~s}$ ) as the $\mathrm{HCl}$ concentration gradually rose to the steadystate value. The hydrodechlorination activity was higher than that of $\mathrm{Pd} / \mathrm{Al}_{2} \mathrm{O}_{3}$, with 63 and $79 \%$ HDC conversion levels, for $180 \mu \mathrm{M}$ and $320 \mu \mathrm{M}$ of TCE inlet concentrations, respectively. It should be noted that the Pd/SOMS initially loaded into the bed was in the closed (unswollen) state. In other words, the catalyst was not pre-treated with an organic solvent (ethanol), which would swell the pores prior to the reaction. The collapsed initial pore architecture may account for the slow approach to steady-state and the long transient period, during which the pores of the SOMS support are expected to be filled by TCE adsorption. In other words, during this period TCE would be concentrating inside the pores. Another interesting observation from these experiments is that $\mathrm{HCl}$ was detected in the effluent for an extended time (1500 s) after discontinuing TCE addition to the deionized feed water. Continued $\mathrm{HCl}$ production can be explained by the reaction continuing from the reservoir of adsorbed TCE as well as desorption of retained $\mathrm{HCl}$. The amount of chlorinated solvents in the reactor effluent was measured at $t=$ $1000,2500,5000 \mathrm{~s}\left([\mathrm{TCE}]_{\mathrm{in}}=180,320\right.$, and $0 \mu \mathrm{M}$, respectively). At all-time points, the amount 
of TCE in the reactor effluent water was undetectable by GC-MS. An amount of vinyl chloride approximately $10 \%$ of the TCE effluent concentration was detected when TCE was in stoichiometric excess of $\mathrm{H}_{2}(t=2500 \mathrm{~s})$. Ethane was detected at all-time points, but was not quantified.

The result shown for Pd/SOMS is surprising and significant as it was deduced that the SOMS support itself has a large adsorptive capacity for TCE, resulting in a high concentration of the reactant inside the pores and the ability to "buffer" TCE input loads. An amount of vinyl chloride likely escapes during the elevated TCE input since the vinyl chloride is more soluble in water and likely builds up in the pores due to $\mathrm{H}_{2}$ starvation. The high storage capacity is a unique feature which is facilitated by the swelling and adsorptive characteristics of SOMS. The hydrophobic nature of SOMS, which repels water, but allows adsorption of organics inside the pores appears to improve the kinetics, since local concentration of TCE inside the pores, i.e., in the vicinity of the active sites would be much higher than in the bulk of the liquid.

To examine the effect of volumetrically expanding the pores, Pd/SOMS was first pretreated with ethanol in order to reach its maximum swollen state to make the catalyst pores fully opened prior to reaction. The Pd/SOMS-open was then tested for HDC of TCE (Figure 8 (c)). When the pores are volumetrically expanded by ethanol pre-treatment, a significant increase in the HDC conversion was obtained over the $1 \% \mathrm{Pd} / \mathrm{SOMS}$-open compared to $1 \% \mathrm{Pd} / \mathrm{SOMS}$-closed and $1 \%$ $\mathrm{Pd} / \mathrm{Al}_{2} \mathrm{O}_{3}$ catalysts in both TCE feed concentrations. The $\mathrm{HCl}$ concentration obtained with 180 $\mu \mathrm{M}$ TCE feed reached a maximum value at $94 \%$ of HDC conversion. This is $31 \%$ greater compared to $\mathrm{Pd} / \mathrm{SOMS}$-closed sample. In the second region where $42 \mathrm{ppm}$ of TCE feed was utilized, \%HDC reached $84 \%$. An important observation is that the approach to steady-state i.e., transient period was much shorter $(420 \mathrm{~s})$ for the Pd/SOMS-open sample since the pores were already fully opened when the feed was introduced and the TCE could concentrate inside the pores much faster. Similarly, the production of $\mathrm{HCl}$ was continued for a shorter time (900 s) after addition of TCE to reactant stream was stopped, compared to the Pd/SOMS-closed. This is likely due to the higher conversion rate of the reactant, which results in a faster depletion rate of the TCE "stored" in the pores. Chlorinated solvent concentrations in the effluent were measured at $t$ $=1800,3000,4500 \mathrm{~s}$. TCE and all partially dechlorinated compounds were undetectable at 1800 $\mathrm{s}\left([\mathrm{TCE}]_{\mathrm{in}}=180 \mu \mathrm{M}\right)$ and $4500 \mathrm{~s}\left([\mathrm{TCE}]_{\mathrm{in}}=0 \mu \mathrm{M}\right.$, post addition $)$. When TCE was in excess $(t=$ 
$3000 \mathrm{~s})$ a small amount of TCE $\left(C_{\text {out }} / C_{\text {in }}=0.02\right)$ and vinyl chloride were detected suggesting the open state-SOMS has capability of adsorbing and TCE.

The faster kinetics due to concentration of TCE inside the pores is seen more clearly when the results obtained over $\mathrm{Pd} / \mathrm{Al}_{2} \mathrm{O}_{3}$ and $\mathrm{Pd} / \mathrm{SOMS}$ (both open and closed) are compared. In these experiments, the feed flow rate and concentration were kept constant, but the amount of $\mathrm{Pd} / \mathrm{Al}_{2} \mathrm{O}_{3}$ in the reactor was more than 5 and 7 times that of the $\mathrm{Pd} / \mathrm{SOMS}$ and $\mathrm{Pd} / \mathrm{SOMS}$-open, respectively. This result shows that the high hydrodechlorination rates obtained over Pd/SOMS (both open and closed) cannot be explained by their higher surface areas.

It should be noted that the $\mathrm{pH}$ of the reactant solution could affect the catalytic activity as well as stability. It is also possible that the acidity of the reactant solution may influence the degree of swelling of the Pd/SOMS catalyst. Thus, a comparison study of the catalytic activity of $\mathrm{Pd} / \mathrm{Al}_{2} \mathrm{O}_{3}$ and Pd/SOMS (both open and closed) in basic media would be informative and is under progress.

\subsubsection{Catalytic Activity of $\mathrm{Li}_{2} \mathrm{~S}$ Poisoned $\mathrm{Pd} / \mathrm{SOMS}$ and $\mathrm{Pd} / \mathrm{Al}_{2} \mathrm{O}_{3}$}

Another advantageous aspect of SOMS material is the hydrophobicity which makes the $\mathrm{Pd} / \mathrm{SOMS}$ catalyst considerably resistant to ionic poisons. Various ionic poisons, which exist in groundwater, decrease the performance of the catalyst. Among them, several studies have shown that sulfur containing groups have a significant impact on the stability of Pd-based catalysts used for HDC of TCE. In this study, lithium sulfide $\left(\mathrm{Li}_{2} \mathrm{~S}\right)$ was used as a model poison compound in order to investigate the effectiveness of the hydrophobic SOMS support in protecting the Pd active sites from poisoning.

HDC activity was measured for $1 \% \mathrm{Pd} / \mathrm{SOMS}$ was poisoned ex-situ by soaking in a solution containing 5 ppm of $\mathrm{Li}_{2} \mathrm{~S}$ and 1 ppm $\mathrm{Na}_{2} \mathrm{CO}_{3}$ for $1 \mathrm{hr}$. As a comparison, $1 \% \mathrm{Pd} / \mathrm{Al}_{2} \mathrm{O}_{3}$ was also poisoned using $\mathrm{Li}_{2} \mathrm{~S}$ under the same conditions. Figure 9 (a) and (b) show the catalytic activity data collected over the two $\mathrm{Li}_{2} \mathrm{~S}$-poisoned-samples for HDC of TCE. It is clear that a complete deactivation was observed for the $\mathrm{Pd} / \mathrm{Al}_{2} \mathrm{O}_{3}$ catalyst after poisoning whereas $\mathrm{Pd} / \mathrm{SOMS}$ remained partially active. 
As previously mentioned, the observed initial time lag over Pd/SOMS catalyst was ascribed to the adsorption time of TCE into the pores of the support. However, compared to the fresh $1 \%$ $\mathrm{Pd} / \mathrm{SOMS}-c l o s e d$, the approach to steady state was slower (850 s vs 4100 s), i.e., more time was required to reach to the same conversion at steady-state for the poisoned sample. The vapor phase adsorption of TCE to $\mathrm{Pd} / \mathrm{Al}_{2} \mathrm{O}_{3}$ and $\mathrm{Pd} / \mathrm{SOMS}$ before and after poisoning was measured (Figure 10). Similar to other organic vapors, Pd/SOMS has a high adsorption capacity for TCE, $125 \% \mathrm{w} / \mathrm{w}$, which is $10 \mathrm{x}$ more that the amount of TCE adsorbed by $\mathrm{Pd} / \mathrm{Al}_{2} \mathrm{O}_{3}$. Exposure of $\mathrm{Pd} / \mathrm{SOMS}$ to $\mathrm{Li}_{2} \mathrm{~S}$ had no deleterious effect on the TCE adsorption, indicating that the slower activity is due to changes in catalyst activity and not the affinity of the sorbent support. The slower rise time is likely due to poisoning of Pd particles near the surface of the SOMS support whereas particles deeper in the hydrophobic matrix appear to be protected from sulfide. TCE must adsorb further into the pores to reach active catalyst. A longer time-lag was also seen when the TCE flow was stopped in which more than 50 min was spent to release all the adsorbed TCE molecules. These data indicate that the SOMS matrix can exclude anionic poisons, especially if the particles are embedded in the matrix where aqueous solutions cannot penetrate.

To further investigate TCE adsorption behavior over the $\mathrm{Pd} / \mathrm{SOMS}$ and $\mathrm{Pd} / \mathrm{Al}_{2} \mathrm{O}_{3}$ catalysts, in situ DRIFTS experiments were performed during TPD. As seen in Figure 11, adsorption of TCE on both catalysts was observed, as manifested through the bands at 781,841 and $940 \mathrm{~cm}^{-1}$ for $\mathrm{Pd} / \mathrm{SOMS}$ and 783, 845 and $943 \mathrm{~cm}^{-1}$ for $\mathrm{Pd} / \mathrm{Al}_{2} \mathrm{O}_{3}$ catalysts [53]. These bands are assigned to C$\mathrm{Cl}\left(781\right.$ and $\left.940 \mathrm{~cm}^{-1}\right)$ and $\mathrm{C}-\mathrm{H}$ bending $\left(841 \mathrm{~cm}^{-1}\right)$ vibrations of the TCE molecules that were maintained even at elevated temperatures [53]. The 1581 and $1556 \mathrm{~cm}^{-1}$ peaks are associated to $\mathrm{C}=\mathrm{C}$ bond of TCE [53], and possibly related to the molecularly adsorbed TCE on the catalyst surface.

There are two major differences between the spectra of $\mathrm{Pd} / \mathrm{SOMS}$ and $\mathrm{Pd} / \mathrm{Al}_{2} \mathrm{O}_{3}$. One is the band at $1640 \mathrm{~cm}^{-1}$, which is not seen over $\mathrm{Pd} / \mathrm{SOMS}$, but is present in $\mathrm{Pd} / \mathrm{Al}_{2} \mathrm{O}_{3}$ spectrum with significant intensity. This band can be assigned to adsorbed water on the catalyst surface [54]. These results exhibit the strong hydrophobicity of the $\mathrm{Pd} / \mathrm{SOMS}$ sample compared to $\mathrm{Pd} / \mathrm{Al}_{2} \mathrm{O}_{3}$. Another difference is that the bands 1450 and $1550 \mathrm{~cm}^{-1}$, which were observed over $\mathrm{Pd} / \mathrm{Al}_{2} \mathrm{O}_{3}$ catalyst above $100{ }^{\circ} \mathrm{C}$, and, which can be assigned to carboxylate-type species, were not seen in the spectra of Pd/SOMS [55]. Chintawar and Greene performed a similar study using $\mathrm{Cr}-\mathrm{Y}$ 
catalyst and reported monochloroacetate $\left(\mathrm{CH}_{2} \mathrm{Cl}^{-} \mathrm{COO}^{-}\right)$as an intermediate compound [56]. The formation of monochloroacetate indicates participation of surface oxygen of $\mathrm{Al}_{2} \mathrm{O}_{3}$ support during TCE adsorption. The lack of similar features over the Pd/SOMS spectra may be due weaker bonds to the surface which may result in short-lived surface species. It is also possible that adsorption of TCE may go through a different intermediate over Pd/SOMS.

\subsection{Pd Leaching with $\mathrm{HCl}$}

Catalyst deactivation due to $\mathrm{HCl}$ was investigated since $\mathrm{HCl}$ is a potential inhibitory product of the HDC of TCE reaction. The chloride ions interact with Pd active sites, they may affect the oxidation state of $\mathrm{Pd}$, or facilitate the carbon deposition on the catalyst surface $[15,25]$. Besides, Pd leaching has been reported due to decrease in $\mathrm{pH}$ during hydrodechlorination reactions [32, 57]. Similar to the previous sulfur poisoning studies, it was expected that the hydrophobicity of the $\mathrm{Pd} / \mathrm{SOMS}$ catalyst may provide some protection by repelling the $\mathrm{Cl}^{-}$ions. However, it is possible that the resistance to chloride may decay when high concentration of $\mathrm{HCl}$ is used. To allow comparison, both $\mathrm{Pd} / \mathrm{SOMS}$ and $\mathrm{Pd} / \mathrm{Al}_{2} \mathrm{O}_{3}$ were treated ex-situ using $1 \mathrm{M} \mathrm{HCl}$ and characterized using XPS, STEM/EDAX and ICP-OES techniques.

\subsubsection{XPS Results}

Figure 12 (a) shows the $\mathrm{Cl} 2 \mathrm{p}$ spectra collected over the $\mathrm{HCl}$-treated $\mathrm{Pd} / \mathrm{SOMS}$ and $\mathrm{Pd} / \mathrm{Al}_{2} \mathrm{O}_{3}$ samples. The high intensity of the peak validates that $\mathrm{Cl}$ ions were adsorbed on the $\mathrm{Pd} / \mathrm{Al}_{2} \mathrm{O}_{3}$ catalyst surface in contrast to $\mathrm{Pd} / \mathrm{SOMS}$ sample where no $\mathrm{Cl}$ signal was detected. Regarding the Si $2 p$ spectra, no oxidation state change of the $\mathrm{Si}$ was observed. The peak at $102.5 \mathrm{eV}$ indicates that $\mathrm{Si}$ species consist lower oxidation state (1+ and 2+) including features of SiC peak [58-60]. The spectra for $\mathrm{Pd} 3 \mathrm{~d}$ for $\mathrm{Pd} / \mathrm{Al}_{2} \mathrm{O}_{3}$ in Figure 12 (c) were deconvoluted in order to perform quantification of the oxidation state of Pd particles and to understand the change in oxidation states due to $\mathrm{HCl}$ treatment. The peak assignments for $\mathrm{Pd}^{0}$ and $\mathrm{Pd}^{2+}$ were determined based on the literature. [61-63]. The constraints used in fitting the spectra were that the ratio of the intensities of $3 \mathrm{~d}_{3 / 2}$ and $3 \mathrm{~d}_{5 / 2}$ was $2: 3$ and the two peaks were $5.26 \mathrm{eV}$ apart from each other. Since 
the majority of the Pd particles were located inside the SOMS structure, no Pd was observed for $\mathrm{Pd} / \mathrm{SOMS}$ (data not shown). However, using the same Pd loading, two distinctive peaks were found in the $\mathrm{Pd} 3 \mathrm{~d}$ spectra over the pre-reduced $\mathrm{Pd} / \mathrm{Al}_{2} \mathrm{O}_{3}$ catalyst. These results demonstrate that the Pd is embedded in the SOMS support. The effect of $\mathrm{HCl}$ treatment on the oxidation state of Pd on the $\mathrm{Al}_{2} \mathrm{O}_{3}$ support was apparent where a significant decrease in Pd signal intensity was observed due to Pd leaching. Furthermore, the oxidation state of Pd was increased from 0.12 (pre-reduced) to 1.98 after $\mathrm{HCl}$ treatment. This may be attributed to the formation of $\mathrm{PdCl}^{3-}$ and $\mathrm{PdCl}_{4}{ }^{2-}$ complexes, which indirectly affect the change of oxidation state from $\mathrm{Pd}^{0}$ to $\mathrm{Pd}^{2+}$ by stabilizing Pd in the higher oxidation state [25].

\subsubsection{STEM/EDAX and ICP-OES Results}

STEM and TEM images were taken to observe the particle size and Pd dispersion on SOMS and $\mathrm{Al}_{2} \mathrm{O}_{3}$ supports. Figure 13 (a) presents STEM images of the fresh 1\% Pd/SOMS where white dots represent Pd metals. The Pd metal particles are not homogeneously dispersed on the SOMS support. The particles size varies from in the 0-30 $\mathrm{nm}$ range. In some areas, Pd particles were seen to agglomerate forming aggregates. Heterogeneity may be due to non-uniform $\mathrm{Pd}$ distribution post-drying and/or the chemical reduction process where $\mathrm{BH}_{4}^{-}$must penetrate the pores to reduce $\mathrm{Pd}^{2+}$. In contrast to $\mathrm{Pd} / \mathrm{SOMS}$, the fresh $1 \% \mathrm{Pd} / \mathrm{Al}_{2} \mathrm{O}_{3}$ catalyst (Figure 13 (b)), exhibits a uniform dispersion of Pd metal with a very narrow particle size range of 1-5 nm. Particle size histograms of the images are shown in Figure 14.

STEM images and EDAX spectra were obtained over the $\mathrm{HCl}$-treated $\mathrm{Pd} / \mathrm{Al}_{2} \mathrm{O}_{3}$ catalysts. After the $1 \mathrm{M} \mathrm{HCl}$ treatment, most of the Pd particles were leached from the $\mathrm{Al}_{2} \mathrm{O}_{3}$ support as it is shown in the EDAX spectra which no longer displays a Pd peak (Fig 13(d)). On the other hand, most of the Pd metal was still present in the HCl-treated Pd/SOMS sample (Figure 13 (c)). These results show that the hydrophobicity of the SOMS support plays an important role in protecting the Pd particles from chloride ions.

ICP-OES experiment was carried out to quantify the Pd leaching as well as to compare the chloride resistance of the $\mathrm{Pd} / \mathrm{SOMS}$ and $\mathrm{Pd} / \mathrm{Al}_{2} \mathrm{O}_{3}$ catalysts. The concentration of the $\mathrm{Pd}$ in the filtered solution (post-treatment) was acquired and compared to the original amount of Pd (1\%). 
Based on these measurements, the percentage of Pd leaching was calculated and are shown in Table 2. Results from a control experiment where the catalysts were soaked in water only are also included to isolate the degradation effect due to $\mathrm{HCl}$. As it can be seen, no Pd leaching was observed using the $0 \mathrm{M} \mathrm{HCl}$ (pure water). When the $\mathrm{HCl}$ concentration was increased to $0.1 \mathrm{M}$, $74.4 \%$ of $\mathrm{Pd}$ leached out to the $\mathrm{HCl}$ solution from the $\mathrm{Al}_{2} \mathrm{O}_{3}$ support in contrary to the $\mathrm{Pd} / \mathrm{SOMS}$ in which only $1.6 \%$ of $\mathrm{Pd}$ was leached. At $1 \mathrm{M} \mathrm{HCl}$ concentration, all the Pd particles were removed from the $\mathrm{Al}_{2} \mathrm{O}_{3}$ support as opposed to $6.4 \%$ of $\mathrm{Pd} / \mathrm{SOMS}$. These results show that the $\mathrm{Pd}$ sites over $\mathrm{Pd} / \mathrm{SOMS}$ are better protected against leaching compared to $\mathrm{Pd} / \mathrm{Al}_{2} \mathrm{O}_{3}$.

\subsection{HDC of TCE in the Gas Phase}

In the gas phase, the degree of TCE adsorption by SOMS is much smaller and slower than it is in the liquid phase. Part of this is also due to the higher temperatures used in the gas-phase experiments. As mentioned earlier, the pore-opening process may play an important role for obtaining high catalytic activity since it impacts the accessibility of the $\mathrm{Pd}$ active sites and facilitates the concentration of the reactant (TCE) near the active sites (and potentially allowing $\mathrm{HCl}$ egress). Figure 15 shows a comparison of the TCE conversion on the Pd/SOMS and $\mathrm{Pd} / \mathrm{Al}_{2} \mathrm{O}_{3}$ catalysts. In fresh form, $1 \% \mathrm{Pd} / \mathrm{Al}_{2} \mathrm{O}_{3}$ sample exhibited significantly higher catalytic performance at all temperatures tested compared to Pd/SOMS (fresh). The difference in catalytic activity of the $\mathrm{Pd} / \mathrm{SOMS}$ between liquid and gas phase suggests that opening of the pores in SOMS is a key to its superior catalytic performance in the liquid phase HDC of TCE. The fact that $\mathrm{Pd}$ is embedded in SOMS helps the kinetics (including protection from anionic poisons), but may lead to a barrier to activity unless there is sufficient adsorption of TCE inside the pores.

The samples treated by $1 \mathrm{M} \mathrm{HCl}$ were also tested for gas-phase HDC of TCE. Due to strong Pd leaching over the $\mathrm{Pd} / \mathrm{Al}_{2} \mathrm{O}_{3}$ catalyst, no conversion of TCE was observed. On the other hand, although the TCE conversion is low, there was almost no difference in terms of the catalytic activity between the fresh and HCl-treated Pd/SOMS. Figure 15 (c) shows the percent loss in TCE conversion over the two samples at 50, 100 and $150,200{ }^{\circ} \mathrm{C}$. These results are significant in reiterating the importance of the pore architecture in SOMS as well as its ability to protect the Pd sites from leaching. 
Lastly, the effect of water on the hydrodechlorination activity of $\mathrm{Pd} / \mathrm{Al}_{2} \mathrm{O}_{3}$ and $\mathrm{Pd} / \mathrm{SOMS}$ was examined, by adding water to the reactant stream. In the presence of water vapor (4\%), significant decrease in TCE conversions were observed over the $\mathrm{Pd} / \mathrm{Al}_{2} \mathrm{O}_{3}$ catalyst in comparison with the case when the feed was water-free. There appears to be a strong inhibition effect with water over $\mathrm{Pd} / \mathrm{Al}_{2} \mathrm{O}_{3}$.

In contrast, no decrease in TCE conversions were observed for Pd/SOMS sample with water. This indicates that the strong hydrophobicity of the SOMS support plays an important role for alleviating the water inhibition effect. Figure 16 (c) indicates the percent loss in TCE conversion in the presence of water in the TCE reactant stream. Interestingly, when the reaction temperature was increased to $200{ }^{\circ} \mathrm{C}, \mathrm{Pd} / \mathrm{Al}_{2} \mathrm{O}_{3}$ showed better catalytic performance compared to $\mathrm{Pd} / \mathrm{SOMS}$ in the presence of water. This is likely due to a decrease in the hydrophobicity of the SOMS at higher temperatures. When the \%HDC values were compared (not shown), very similar trends were observed in all cases.

\section{Conclusions}

Swellable organically-modified silica was shown to be a promising support for catalysts used for catalytic treatment of water contaminated with chlorinated hydrocarbons, specifically TCE. Both the swelling capability of SOMS and it high hydrophobicity play a role in improving the kinetics of hydrodechlorination of the reaction, by concentrating the organic contaminants inside the pores in the close vicinity of the pores. Pd catalysts supported on SOMS showed a higher HDC activity in the liquid phase compared to $\mathrm{Pd} / \mathrm{Al}_{2} \mathrm{O}_{3}$ catalysts. However, in the gas phase, $\mathrm{Pd} / \mathrm{SOMS}$ was less active than $\mathrm{Pd} / \mathrm{Al}_{2} \mathrm{O}_{3}$. This was attributed to a lesser degree of swelling of the $\mathrm{Pd} / \mathrm{SOMS}$ catalyst in the gas phase. Pd/SOMS catalysts were also shown to be more resistant to deactivation by sulfur compounds or chloride ions than those supported on alumina. Pd species inside the pores of the SOMS support were also shown to be protected against poisoning and leaching in lower pHs. This study demonstrates the potential of these materials as catalyst scaffolds in many applications for catalytic water treatment. 


\section{Acknowledgements}

The financial support for this work was provided by the National Science Foundation through the Grant CBET-1436729. The authors also acknowledge partial support provided by the Ohio Coal Research Consortium. Authors note the efforts of Allison Curtze and Deanna Pickett at The College of Wooster in conducting supporting experiments. 


\section{References}

[1] R.E. Doherty, Environmental Forensics 1 (2000) 69-81.

[2] M.J. Moran, Occurrence and implications of selected chlorinated solvents in ground water and source water in the United States and in drinking water in 12 Northeast and Mid-Atlantic States, 19932002, 2005, pp. i-ix, 1-70.

[3] E.P.A. U.S, Occurrence estimation methodology and occurrence findings report of the six-year review of existing national primary drinking water regulations, Washington, DC, 2003.

[4] E.P.A. U.S, Toxicological Review of Trichloroethylene "In Support of Summary Information on the Integrated Risk Information System (IRIS)", U.S. Environmental Protection Agency, Washington, DC, 2011. [5] H.H. Russell, J.E. Matthews, G.W. Sewell, TCE removal from contaminated soil and ground water. Ground water issue, Environ. Protect. Agency, 1992, p. 12 pp.

[6] W.J. Blanford, E.J. Klingel, G.R. Johnson, R.B. Cain, C. Enfield, M.L. Brusseau, 725 (1999) 167-181.

[7] G.V. Lowry, M. Reinhard, Environmental Science \&amp; Technology 35 (2001) 696-702.

[8] S. Ordóñez, H. Sastre, F.V. Díez, Applied Catalysis B: Environmental 25 (2000) 49-58.

[9] D.I. Kim, D.T. Allen, Industrial \& Engineering Chemistry Research 36 (1997) 3019-3026.

[10] M.G. Davie, H. Cheng, G.D. Hopkins, C.A. LeBron, M. Reinhard, Environmental science \& technology 42 (2008) 8908-8915.

[11] M. Zhang, D.B. Bacik, C.B. Roberts, D. Zhao, Water Research 47 (2013) 3706-3715.

[12] M. Cobo, J. Becerra, M. Castelblanco, B. Cifuentes, J.A. Conesa, Journal of environmental management 158 (2015) 1-10.

[13] B. Schrick, J.L. Blough, A.D. Jones, T.E. Mallouk, Chemistry of Materials 14 (2002) 5140-5147.

[14] C.J. Lin, Y.H. Liou, S.L. Lo, Chemosphere 74 (2009) 314-319.

[15] B.T. Meshesha, N. Barrabés, K. Föttinger, R.J. Chimentão, J. Llorca, F. Medina, G. Rupprechter, J.E. Sueiras, Applied Catalysis B: Environmental 117-118 (2012) 236-245.

[16] B.T. Meshesha, N. Barrabés, J. Llorca, A. Dafinov, F. Medina, K. Föttinger, Applied Catalysis A: General 453 (2013) 130-141.

[17] N. Barrabes, D. Cornado, K. Foettinger, A. Dafinov, J. Llorca, F. Medina, G. Rupprechter, Journal of Catalysis 263 (2009) 239-246.

[18] M.O. Nutt, K.N. Heck, P. Alvarez, M.S. Wong, Applied Catalysis B: Environmental 69 (2006) 115-

125.

[19] M.O. Nutt, J.B. Hughes, M.S. Wong, Environmental Science \& Technology 39 (2005) 1346-1353.

[20] L. Ren, X. Pan, Catalysis Communications 12 (2011) 1366-1369.

[21] H. Takashima, M. Karches, Y. Kanno, Applied Surface Science 254 (2008) 2023-2030.

[22] M. Cobo, C.A. González, E.G. Sánchez, C. Montes, Catalysis Today 172 (2011) 78-83.

[23] E. Díaz, A. McCall, L. Faba, H. Sastre, S. Ordóñez, Environmental Progress \& Sustainable Energy 32 (2013) 1217-1222.

[24] F.-D. Kopinke, K. Mackenzie, R. Koehler, A. Georgi, Applied Catalysis A: General 271 (2004) 119-

128.

[25] S. Ordonez, B.P. Vivas, F.V. Diez, Applied Catalysis B, Environmental 95 (2010) 288-296.

[26] W. Nishijima, Y. Ochi, T.-Y. Tsai, Y. Nakano, M. Okada, Applied Catalysis B: Environmental 51 (2004) 135-140.

[27] S. Ordóñez, H. Sastre, F.V. Díez, Thermochimica Acta 379 (2001) 25-34.

[28] S. Ordóñez, F.V. Díez, H. Sastre, Applied Catalysis B: Environmental 31 (2001) 113-122.

[29] N. Munakata, M. Reinhard, Applied Catalysis B: Environmental 75 (2007) 1-10.

[30] G.V. Lowry, M. Reinhard, Environmental science \& technology 34 (2000) 3217-3223. 
[31] F.-D. Kopinke, D. Angeles-Wedler, D. Fritsch, K. Mackenzie, Applied Catalysis B: Environmental 96 (2010) 323-328.

[32] R. Navon, S. Eldad, K. Mackenzie, F.-D. Kopinke, Applied Catalysis B: Environmental 119-120 (2012) 241-247.

[33] C.M. Burkett, P.L. Edmiston, Journal of Non-Crystalline Solids 351 (2005) 3174-3178.

[34] C.M. Burkett, L.A. Underwood, R.S. Volzer, J.A. Baughman, P.L. Edmiston, Chemistry of Materials 20 (2008) 1312-1321.

[35] P.L. Edmiston, L.A. Underwood, Separation and Purification Technology 66 (2009) 532-540.

[36] P.L. Edmiston, Swellable sol-gels, methods of making, and use thereof, in: U.S. Patent (Ed.), C08G77/60 ed., Abs Materials, Inc., United States, 2012.

[37] P.L. Edmiston, Swellable materials and methods of use in: U.S. Patent (Ed.), C08G77/60 ed., Abs Materials, Inc., United States, 2013.

[38] F.A. Miller, Journal of Raman spectroscopy 19 (1988) 219-221.

[39] D.A. Oriero, A.T. Weakley, D.E. Aston, Science and Technology of Advanced Materials (2016).

[40] N. Colthup, Introduction to infrared and Raman spectroscopy, Elsevier, 2012.

[41] A. Martinelli, International Journal of Molecular Sciences 15 (2014) 6488-6503.

[42] A. Bertoluzza, C. Fagnano, M.A. Morelli, V. Gottardi, M. Guglielmi, Journal of Non-Crystalline Solids 48 (1982) 117-128.

[43] R. Lorenzi, S. Brovelli, F. Meinardi, A. Lauria, N. Chiodini, A. Paleari, Journal of non-crystalline solids 357 (2011) 1838-1841.

[44] D.J. Little, M. Ams, P. Dekker, G.D. Marshall, J.M. Dawes, M.J. Withford, Opt. Express 16 (2008) 20029-20037.

[45] G. Socrates, Infrared and Raman characteristic group frequencies: tables and charts, John Wiley \& Sons, 2004.

[46] B.A. Morrow, The Journal of Physical Chemistry 81 (1977) 2663-2666.

[47] P.J. Launer, Silicone compounds register and review 100 (1987).

[48] F. Galeener, G. Lucovsky, Physical Review Letters 37 (1976) 1474.

[49] M. Payne, J. Inkson, Journal of non-crystalline solids 68 (1984) 351-360.

[50] S. De Leeuw, M.F. Thorpe, Physical review letters 55 (1985) 2879.

[51] R.M. Almeida, C.G. Pantano, Journal of Applied Physics 68 (1990) 4225-4232.

[52] D. Lin-Vien, N.B. Colthup, W.G. Fateley, J.G. Grasselli, The handbook of infrared and Raman characteristic frequencies of organic molecules, Elsevier, 1991.

[53] J. Fan, J.T. Yates, Journal of the American Chemical Society 118 (1996) 4686-4692.

[54] E. Mendelovici, R. Villalba, A. Sagarzazu, O. Carias, Clay Minerals 30 (1995) 307-313.

[55] B. de Rivas, R. López-Fonseca, J.R. González-Velasco, J.I. Gutiérrez-Ortiz, Catalysis Communications 9 (2008) 2018-2021.

[56] P.S. Chintawar, H.L. Greene, Journal of Catalysis 165 (1997) 12-21.

[57] G. Yuan, M.A. Keane, Catalysis Today 88 (2003) 27-36.

[58] H. Watanabe, T. Hosoi, Physics and Technology of Silicon Carbide Devices (2013) 235-250.

[59] M. Kim, J. Kim, Physical Chemistry Chemical Physics 16 (2014) 11323-11336.

[60] A. Yamashita, Y. Sato, T. Tsukamoto, Y. Suda, Applied Physics Express 7 (2014) 074203.

[61] R. Wojcieszak, M. Ghazzal, E.M. Gaigneaux, P. Ruiz, Catalysis Science \& Technology 4 (2014) 738-

745.

[62] D. Wang, S. Lu, P.J. Kulesza, C.M. Li, R. De Marco, S.P. Jiang, Physical Chemistry Chemical Physics 13 (2011) 4400-4410.

[63] X. Liu, G. Xu, Y. Chen, T. Lu, Y. Tang, W. Xing, Scientific reports 5 (2015). 


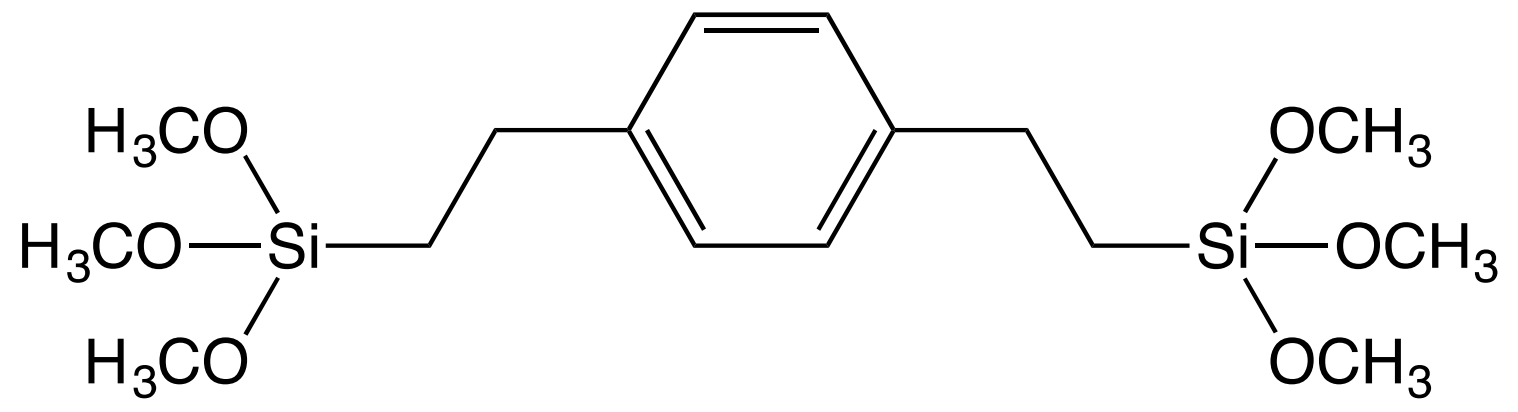

Figure 1. Bis(trimethoxysilylethyl)benzene (BTEB) 


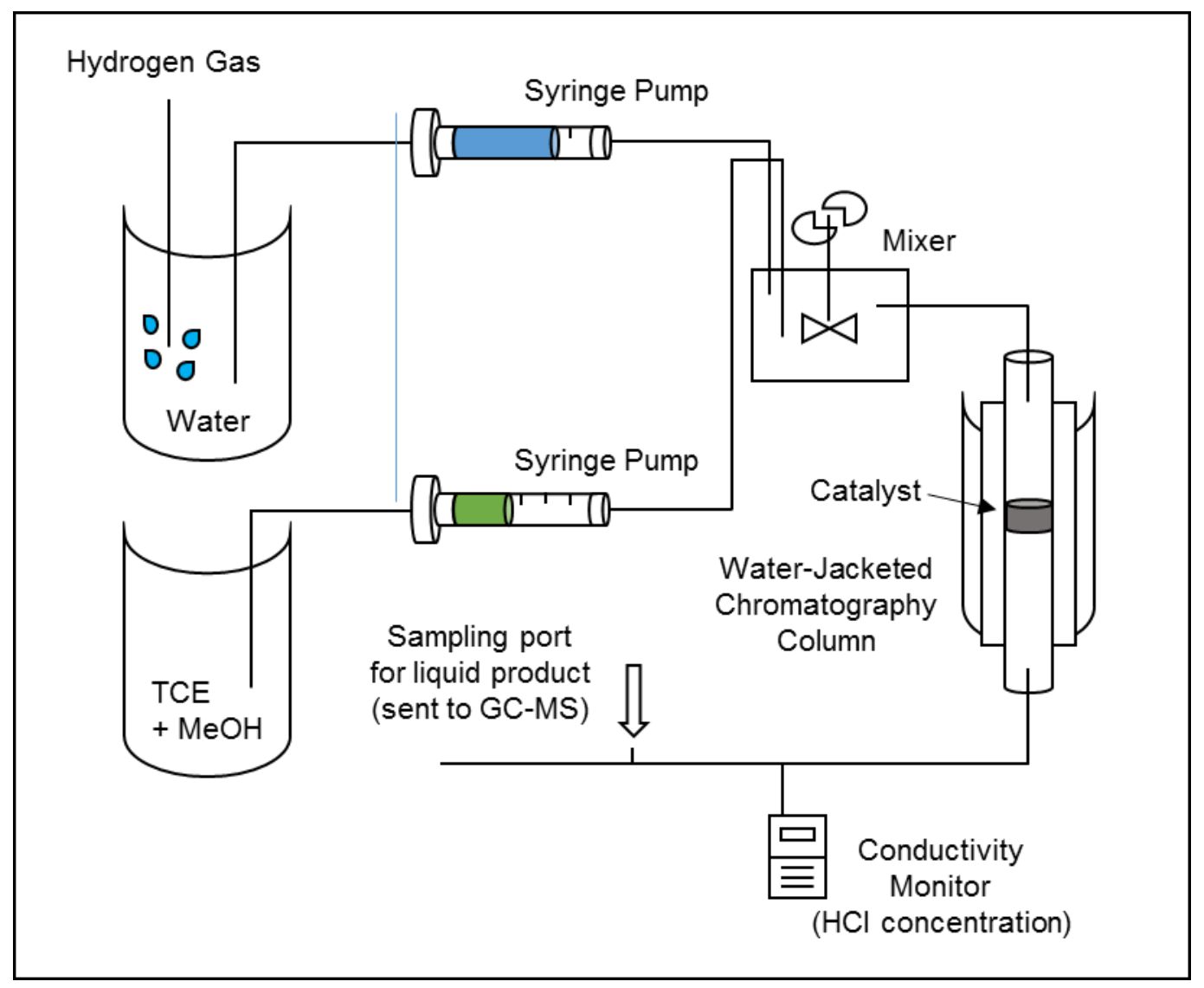

Figure 2. Diagram of the liquid phase reactor system including a continuous flow of reactants and a fixed bed reactor 


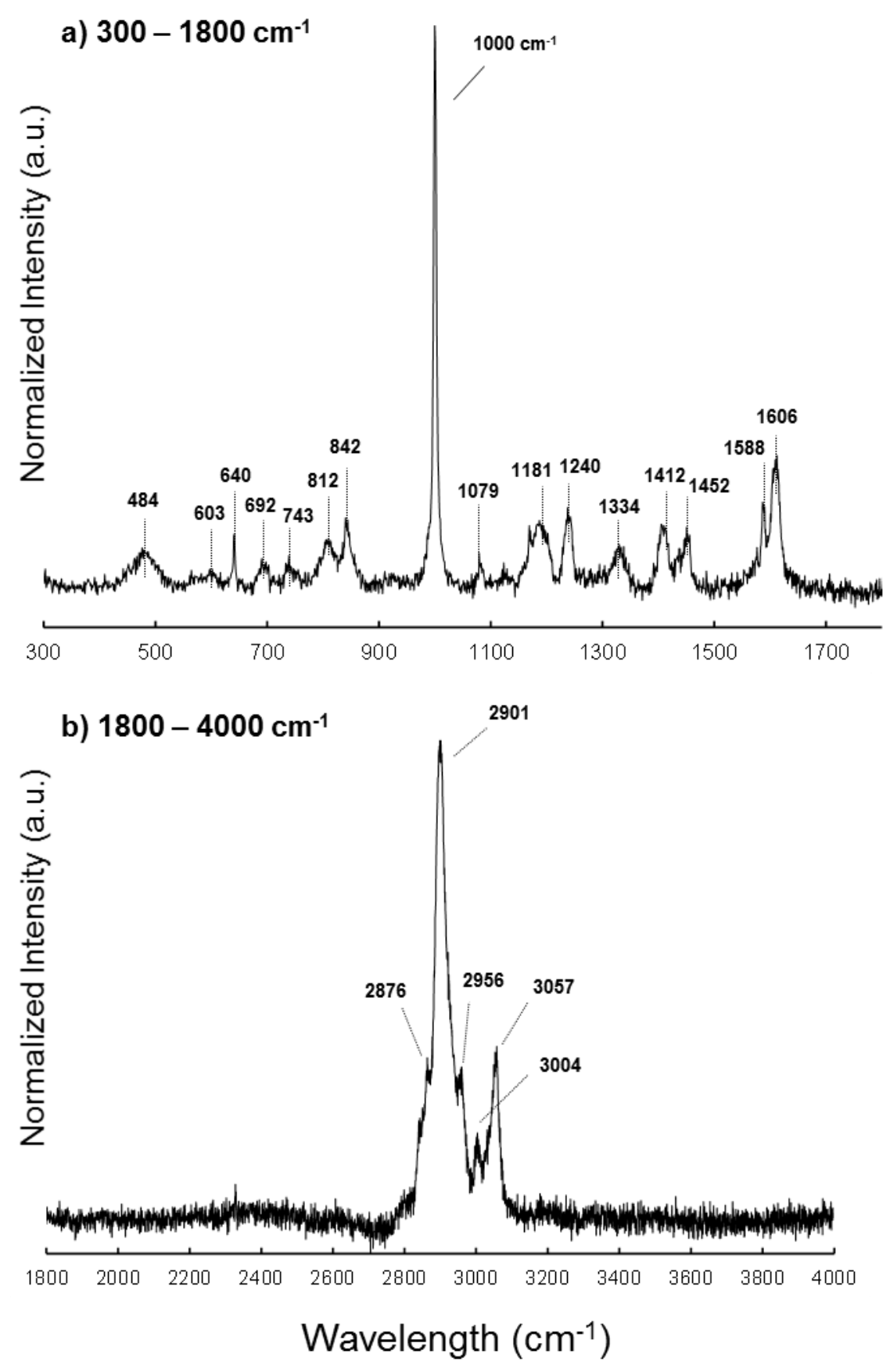

Figure 3. Raman spectra of SOMS, a) $300-1800 \mathrm{~cm}^{-1}$ and b) $1800-4000 \mathrm{~cm}^{-1}$ 


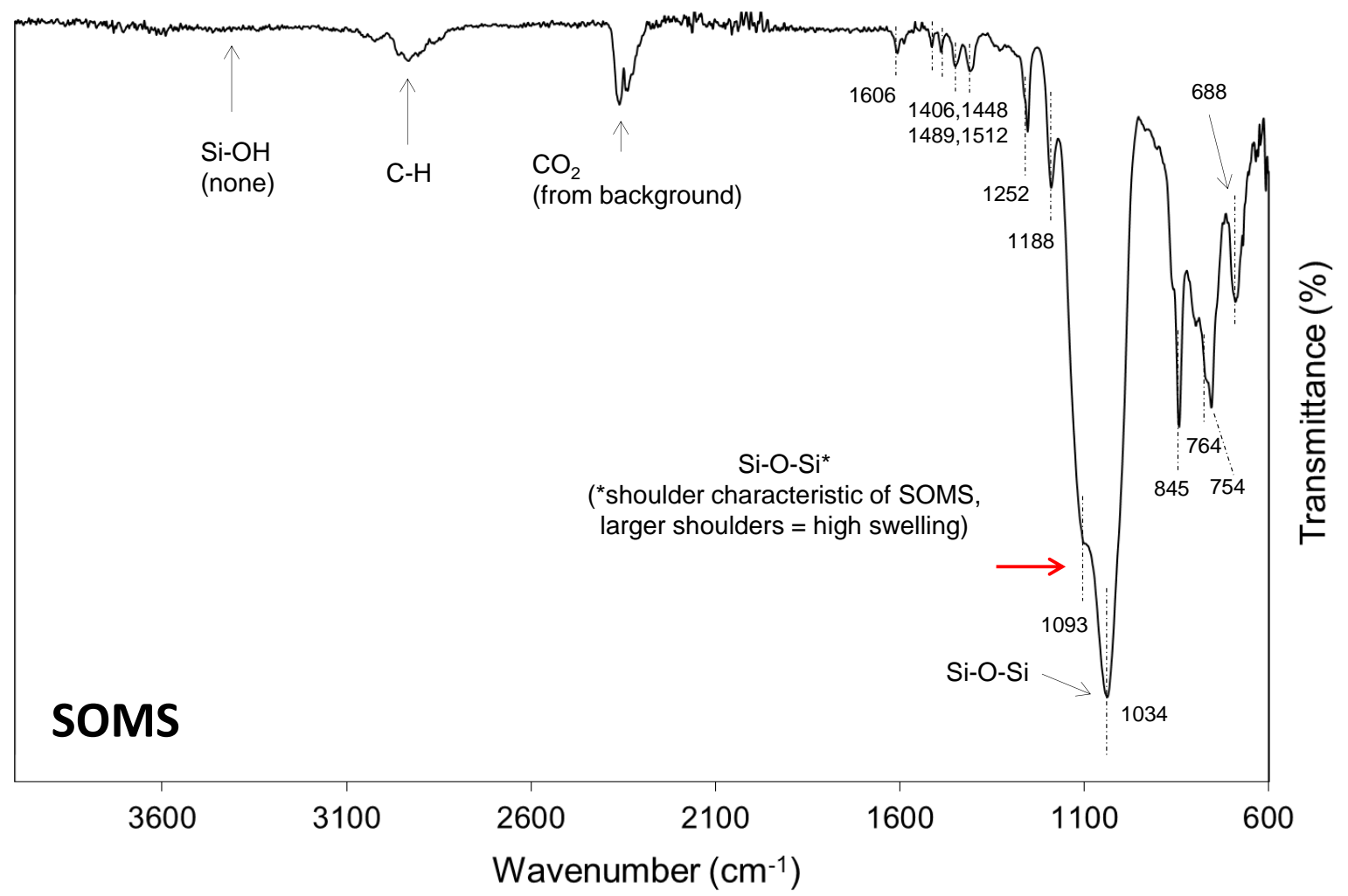

Figure 4. IR spectra of SOMS 


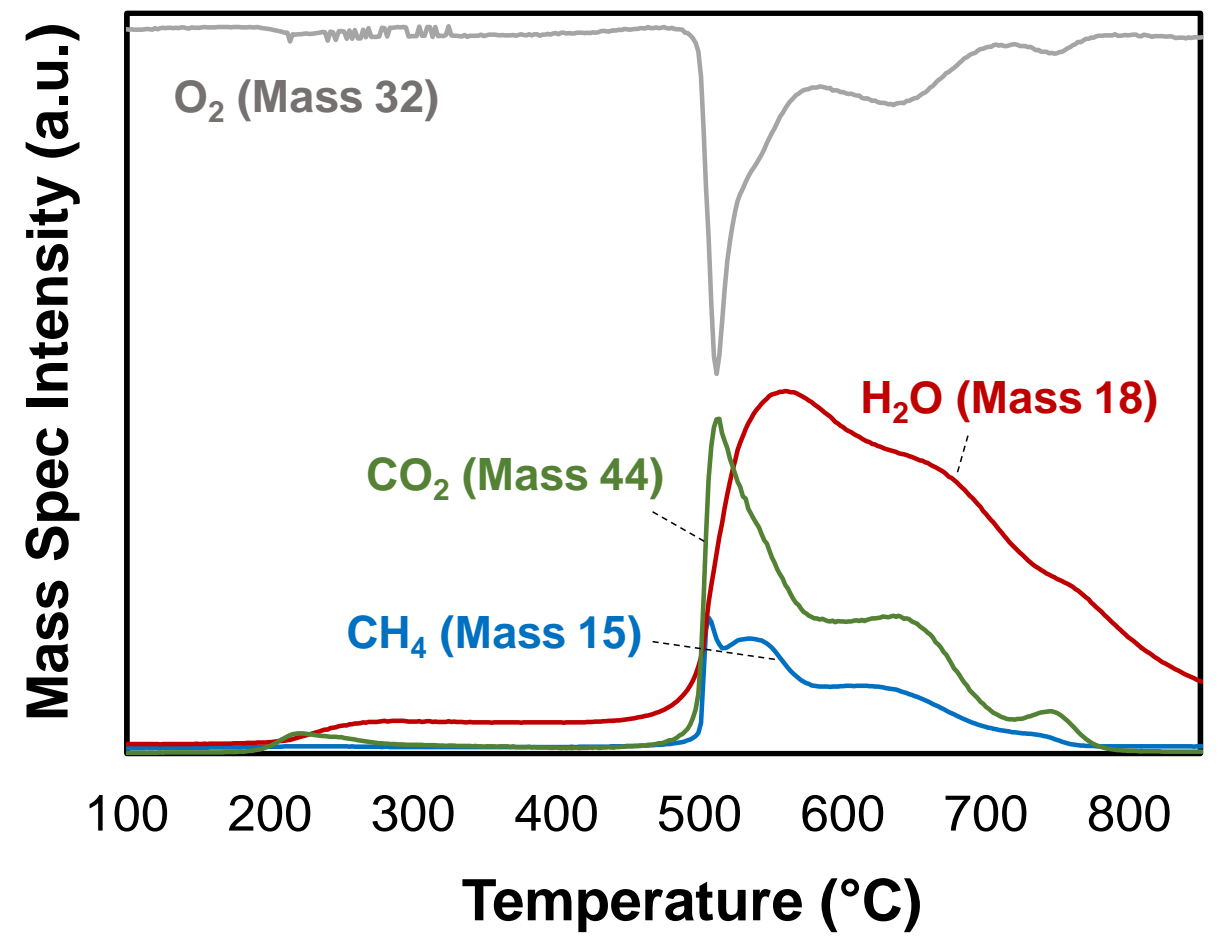

Figure 5. Temperature-programmed oxidation (TPO) profiles showing decomposition of SOMS at high temperatures $\left(>450^{\circ} \mathrm{C}\right)$ 


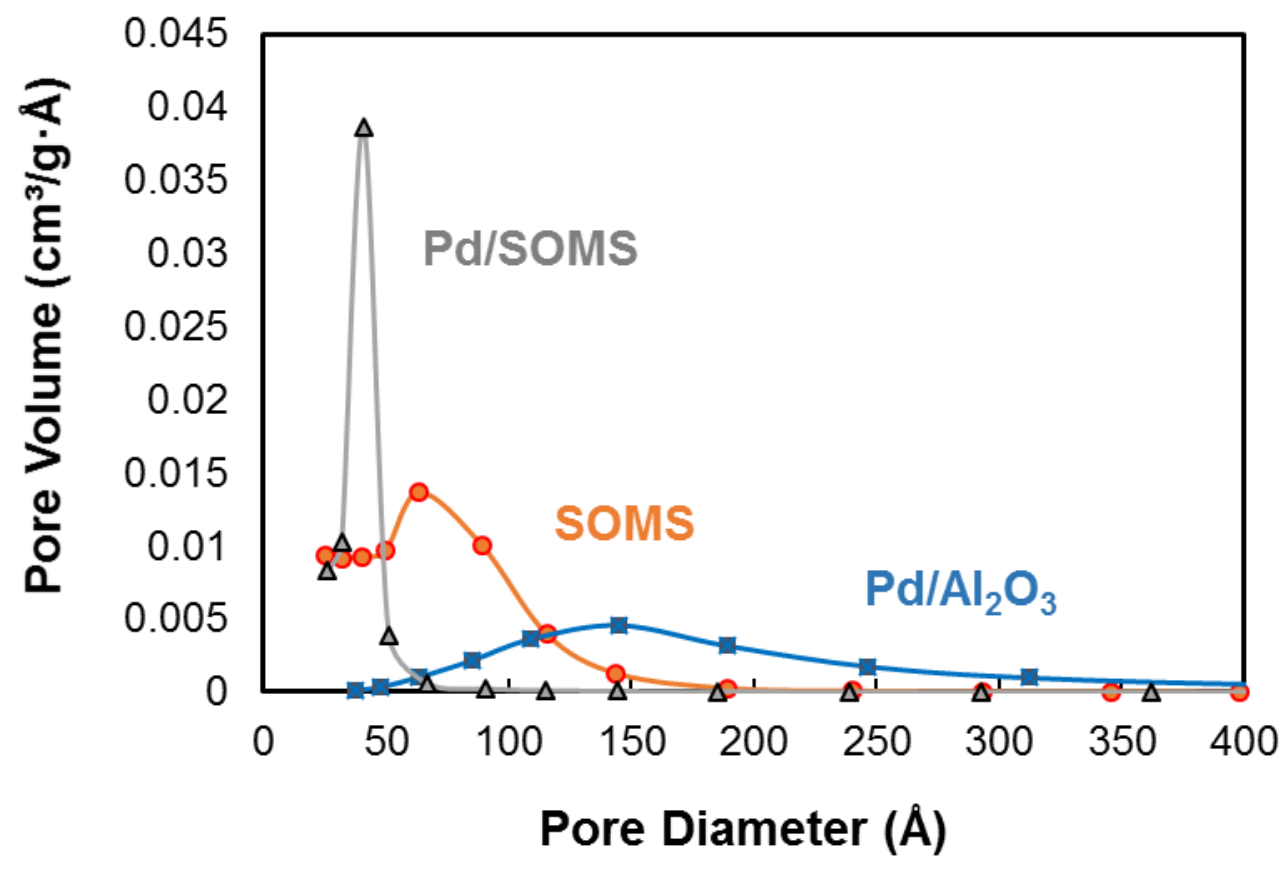

Figure 6. BJH Pore size distribution of SOMS, $1 \% \mathrm{Pd} / \mathrm{SOMS}$ and $1 \% \mathrm{Pd} / \mathrm{Al}_{2} \mathrm{O}_{3}$ 

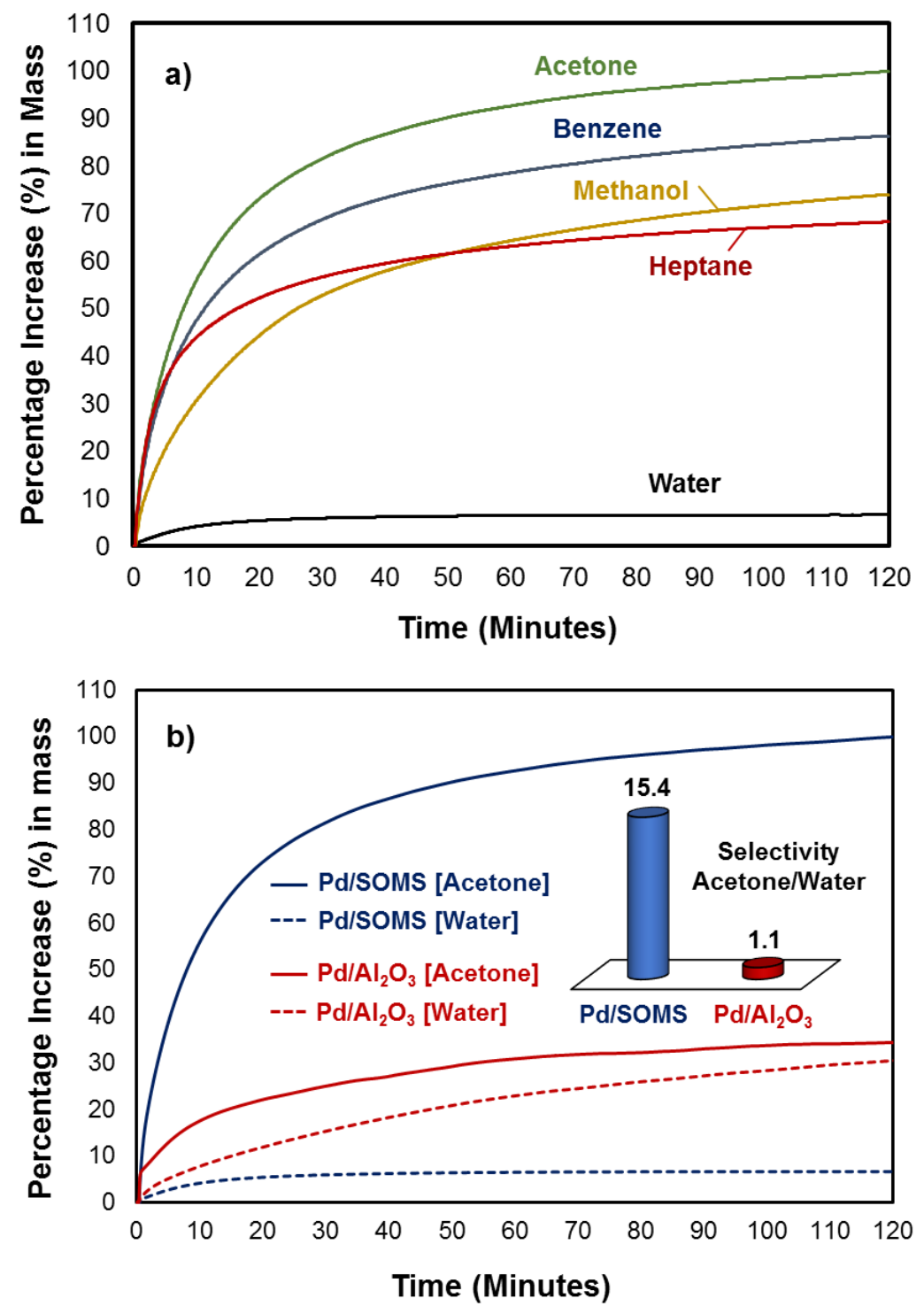

Figure 7. a) Adsorption of different organic groups on $1 \% \mathrm{Pd} / \mathrm{SOMS}$, b) Adsorption of water and acetone on $1 \% \mathrm{Pd} / \mathrm{SOMS}$ and $1 \% \mathrm{Pd} / \mathrm{Al}_{2} \mathrm{O}_{3}$ catalysts 

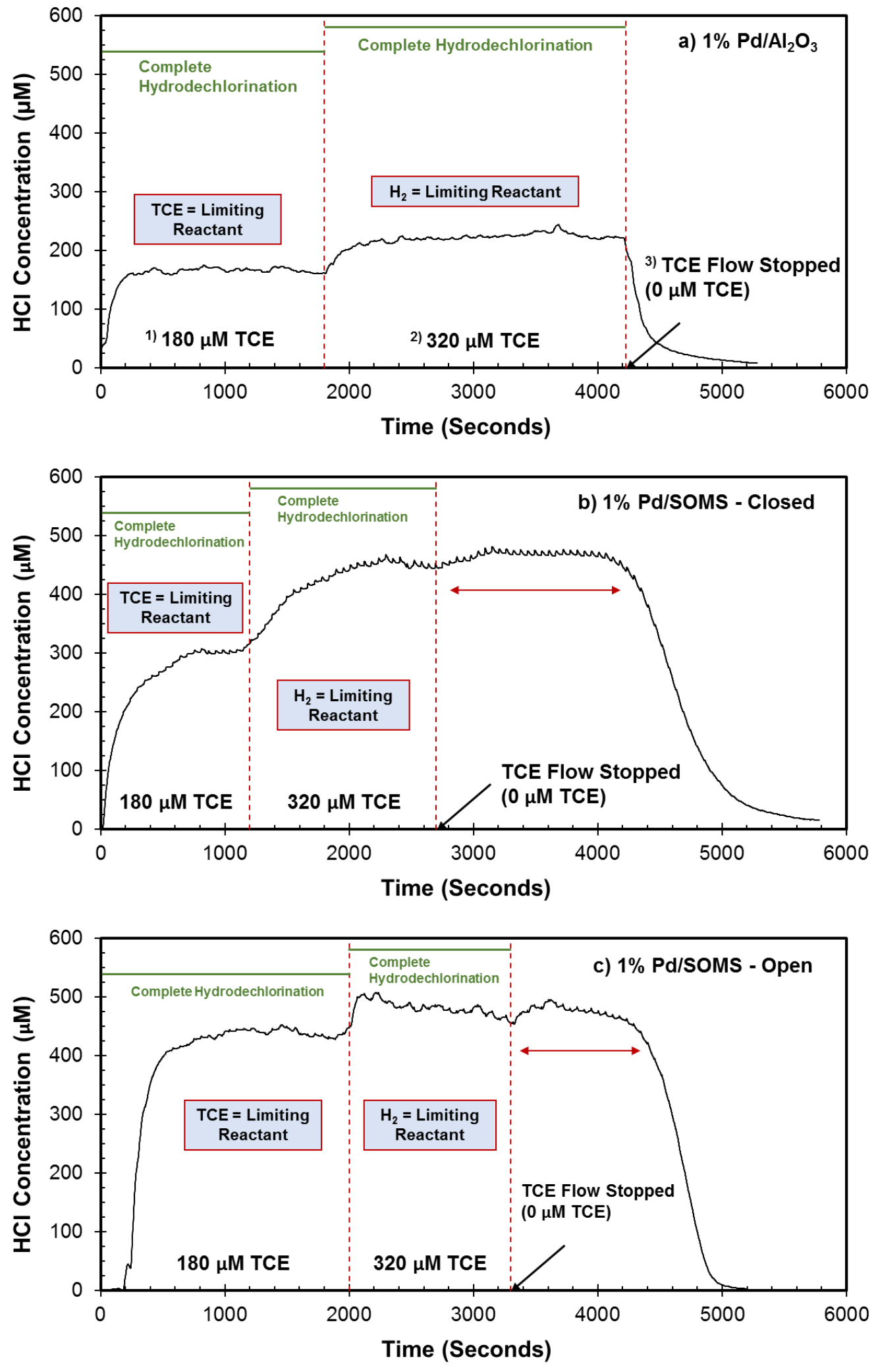

Figure 8. Catalytic activity data for a) $1 \% \mathrm{Pd} / \mathrm{Al}_{2} \mathrm{O}_{3}$, b) $1 \% \mathrm{Pd} / \mathrm{SOMS}-$ closed and c) $1 \%$ $\mathrm{Pd} / \mathrm{SOMS}-$ open for HDC of TCE in continuous flow liquid-phase reactor 

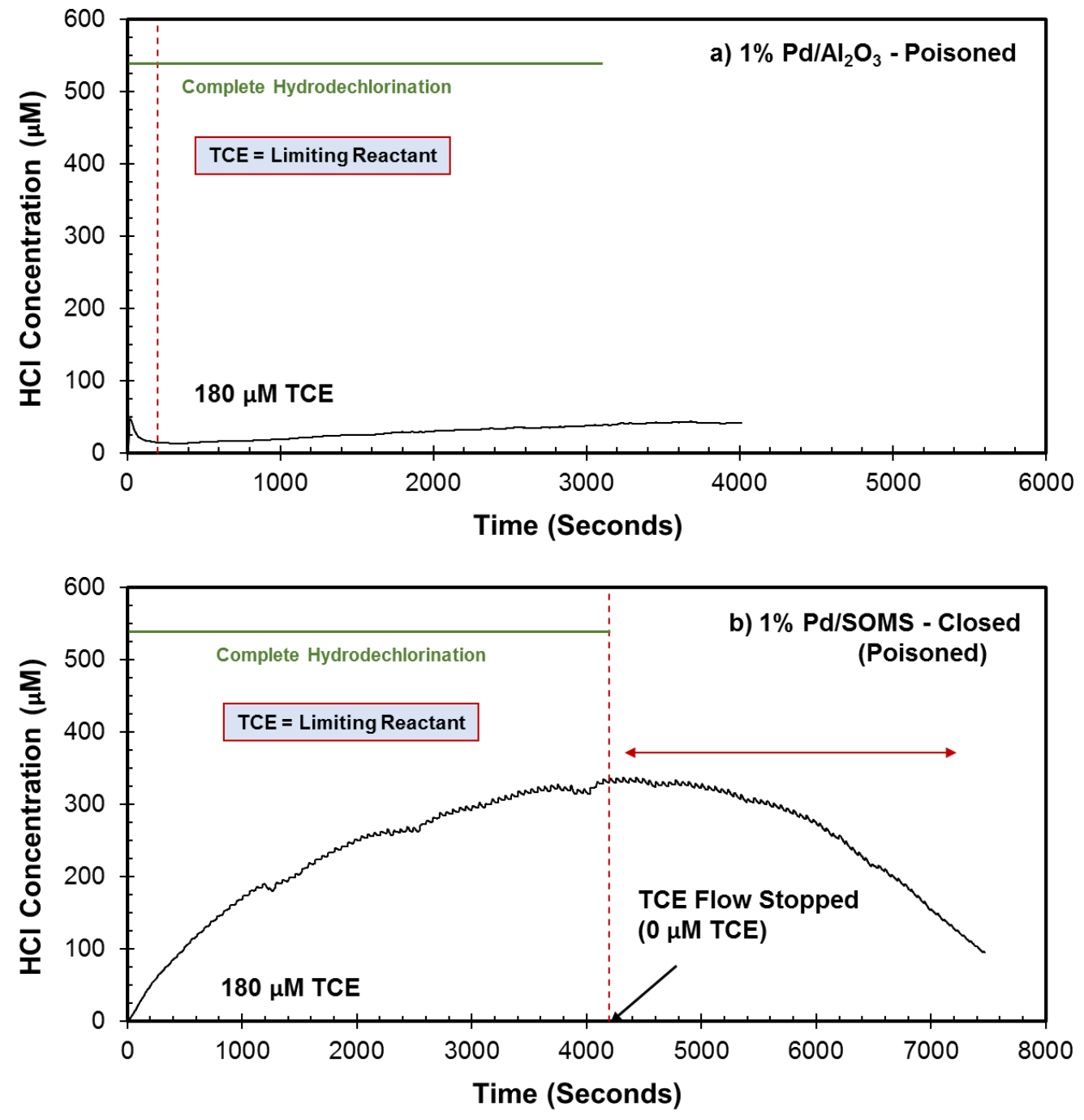

Figure 9. Catalytic activity data for a) $\mathrm{Li}_{2} \mathrm{~S}$-poisoned $1 \% \mathrm{Pd} / \mathrm{Al}_{2} \mathrm{O}_{3}$ and b) $\mathrm{Li}_{2} \mathrm{~S}$-poisoned $1 \% \mathrm{Pd} / \mathrm{SOMS}$ - closed for HDC of TCE in continuous flow liquid-phase reactor 


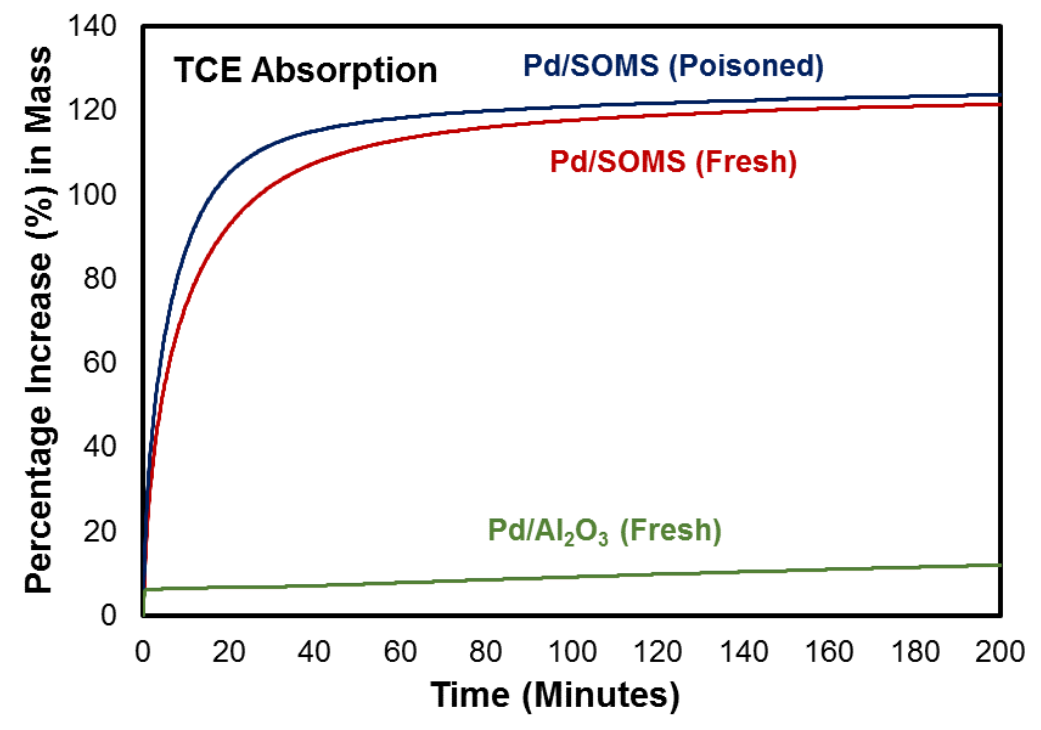

Figure 10. TCE absorption profile for fresh and $\mathrm{Li}_{2} \mathrm{~S}$-poisoned $1 \% \mathrm{Pd} / \mathrm{SOMS}-$ closed and fresh $1 \% \mathrm{Pd} / \mathrm{Al}_{2} \mathrm{O}_{3}$ catalysts 

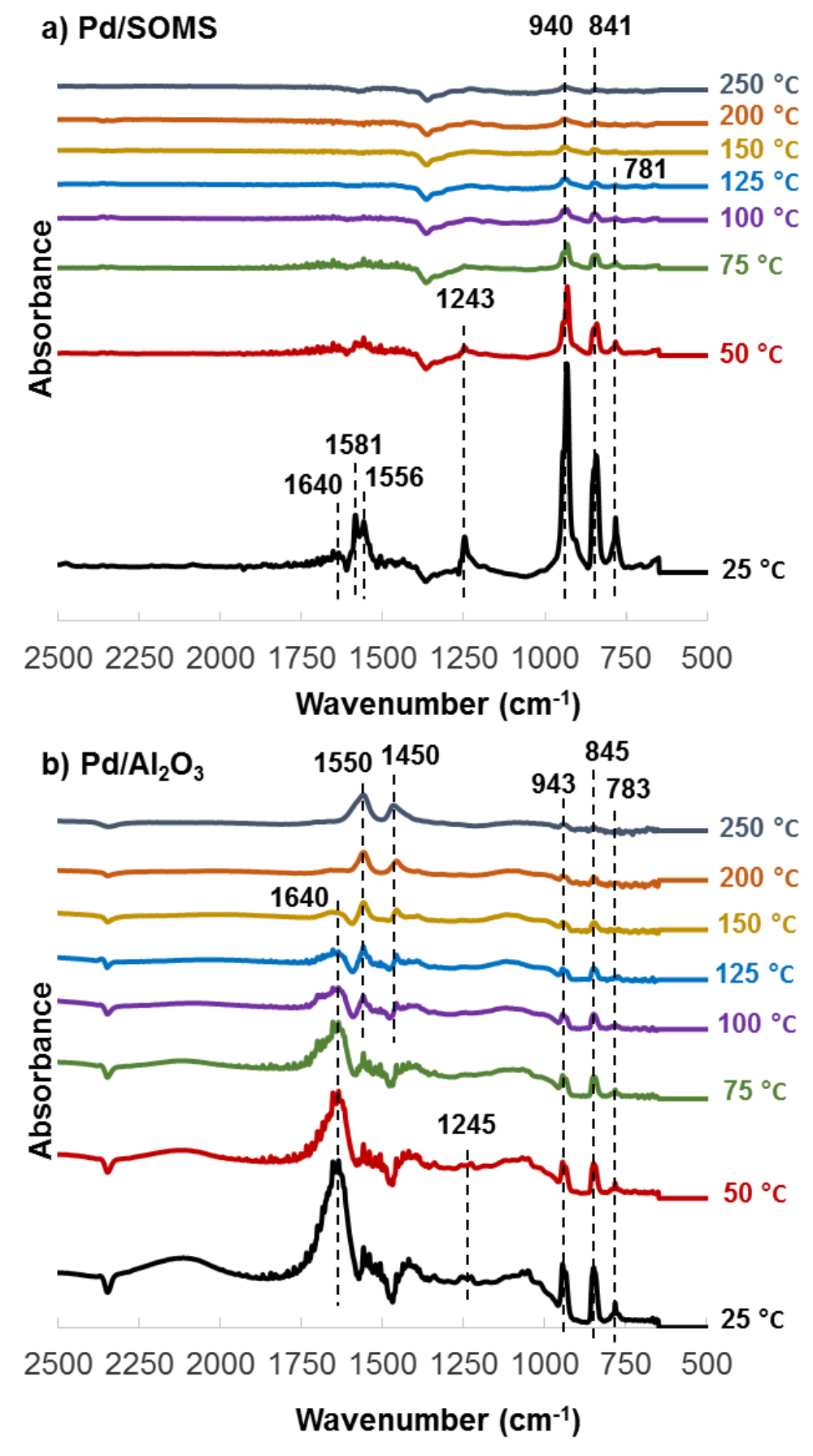

Figure 11. TCE TPD in situ DRIFTS results over $\mathrm{Pd} / \mathrm{SOMS}$ and $\mathrm{Pd} / \mathrm{Al}_{2} \mathrm{O}_{3}$ catalysts 


\section{a) $\mathrm{Cl} 2 \mathrm{p}$}

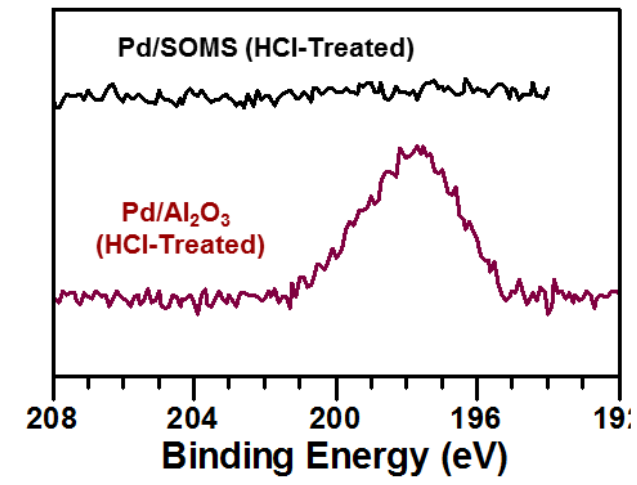

b) Si $2 p$

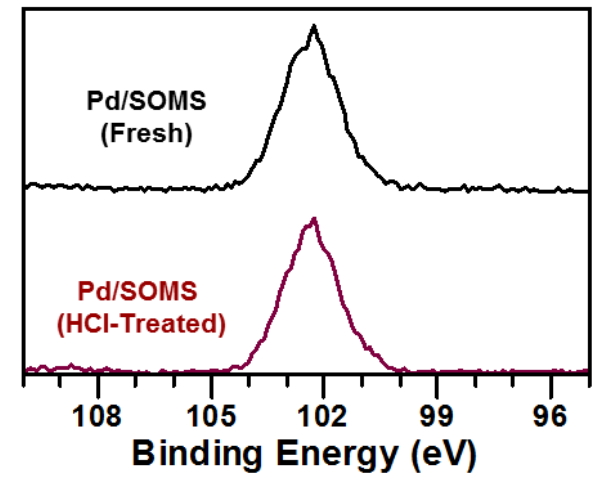

c) Pd 3d

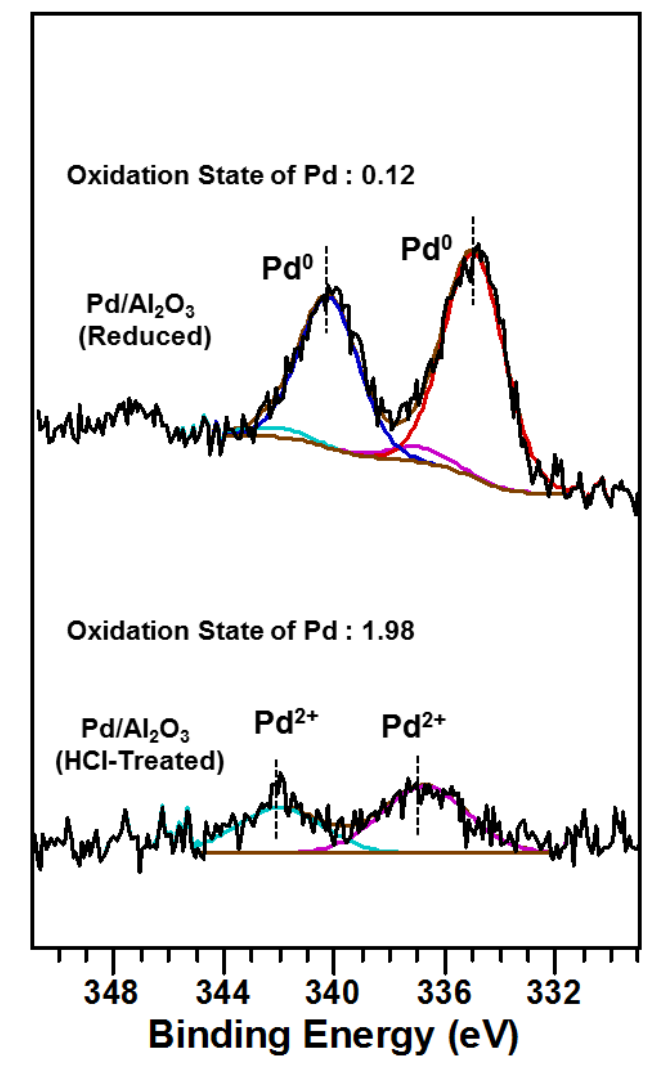

Figure 12. XPS spectra collected over fresh and $\mathrm{HCl}$-treated $1 \% \mathrm{Pd} / \mathrm{SOMS}$ and $1 \%$ $\mathrm{Pd} / \mathrm{Al}_{2} \mathrm{O}_{3}$ catalysts: a) $\mathrm{Cl} 2 \mathrm{p}$, b) Si $2 \mathrm{p}$ and c) $\mathrm{Pd} 3 \mathrm{~d}$ 


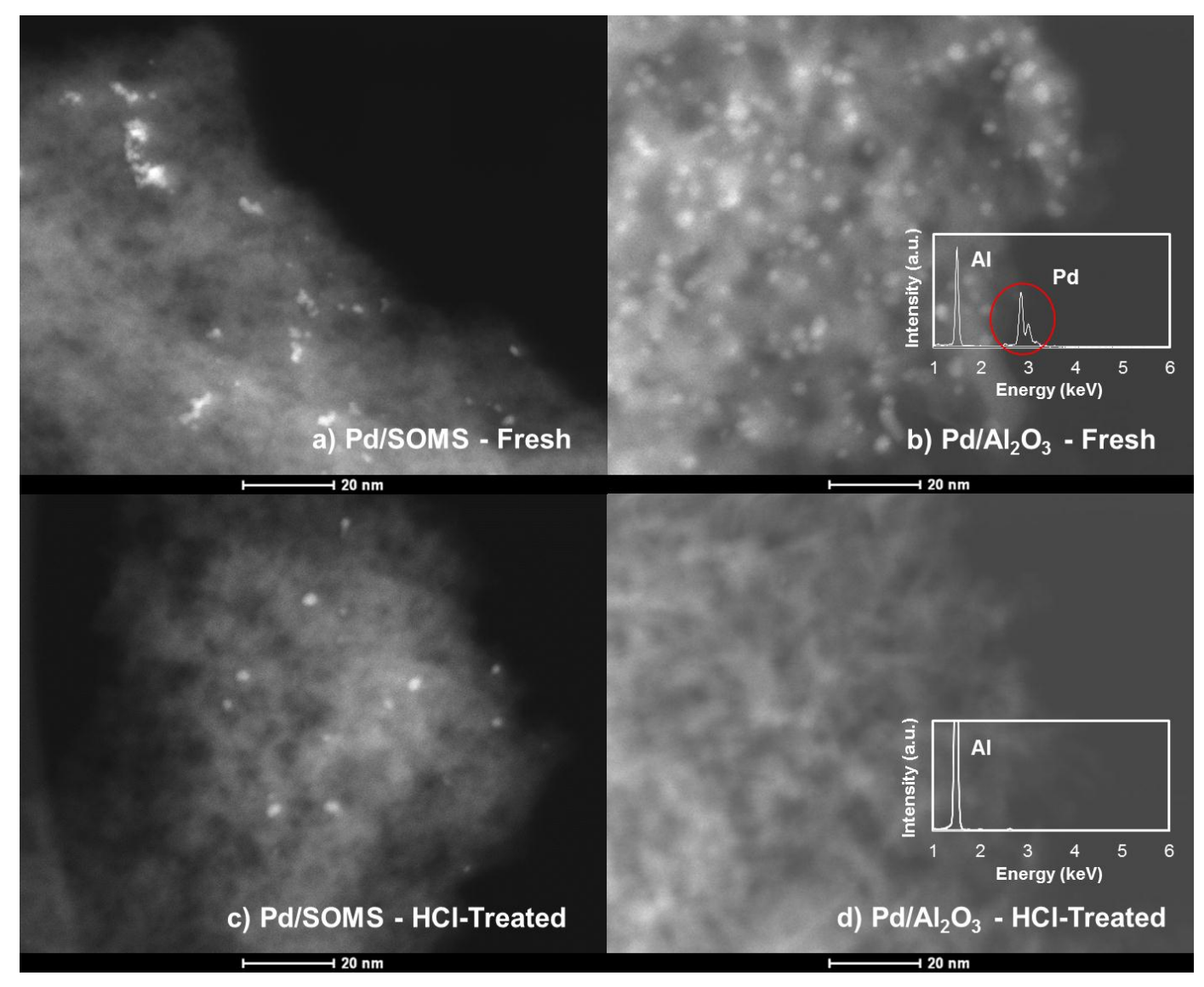

Figure 13. STEM images of fresh and $\mathrm{HCl}$-treated $\mathrm{Pd} / \mathrm{SOMS}$ and $\mathrm{Pd} / \mathrm{Al}_{2} \mathrm{O}_{3}$ catalysts 

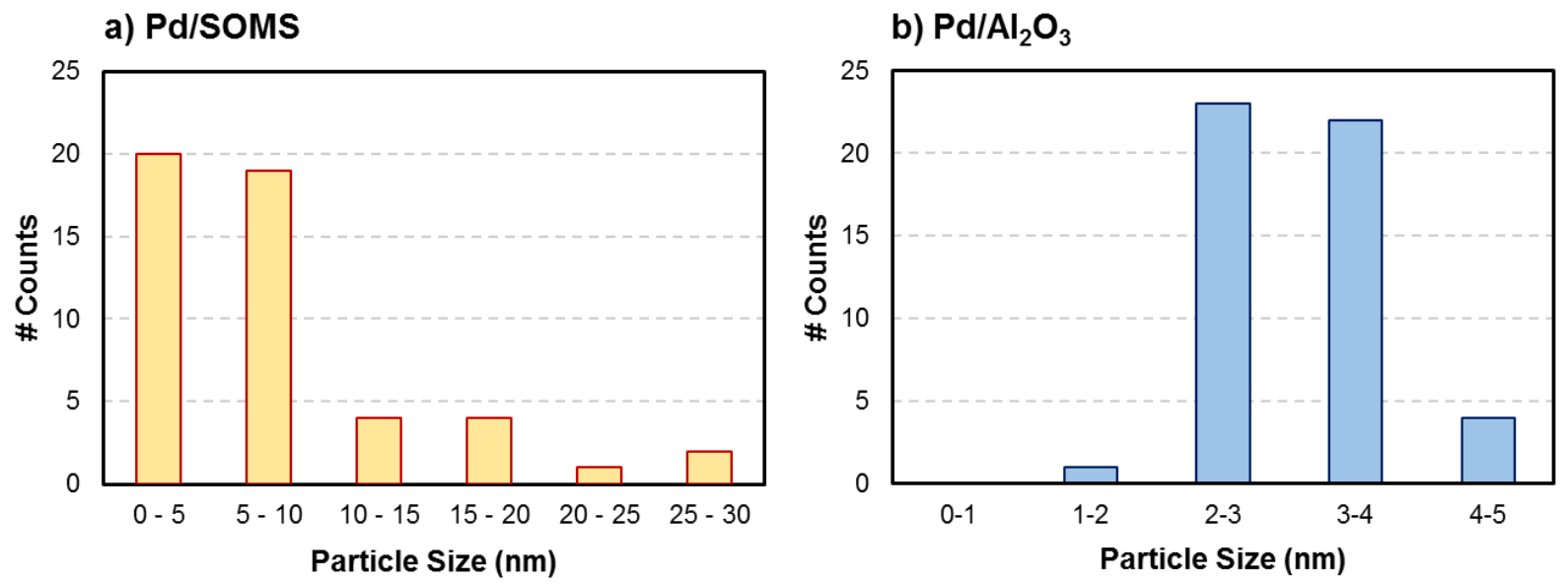

Figure 14. Particle Size Distribution Histogram for $\mathrm{Pd} / \mathrm{SOMS}$ and $\mathrm{Pd} / \mathrm{Al}_{2} \mathrm{O}_{3}$ catalysts 

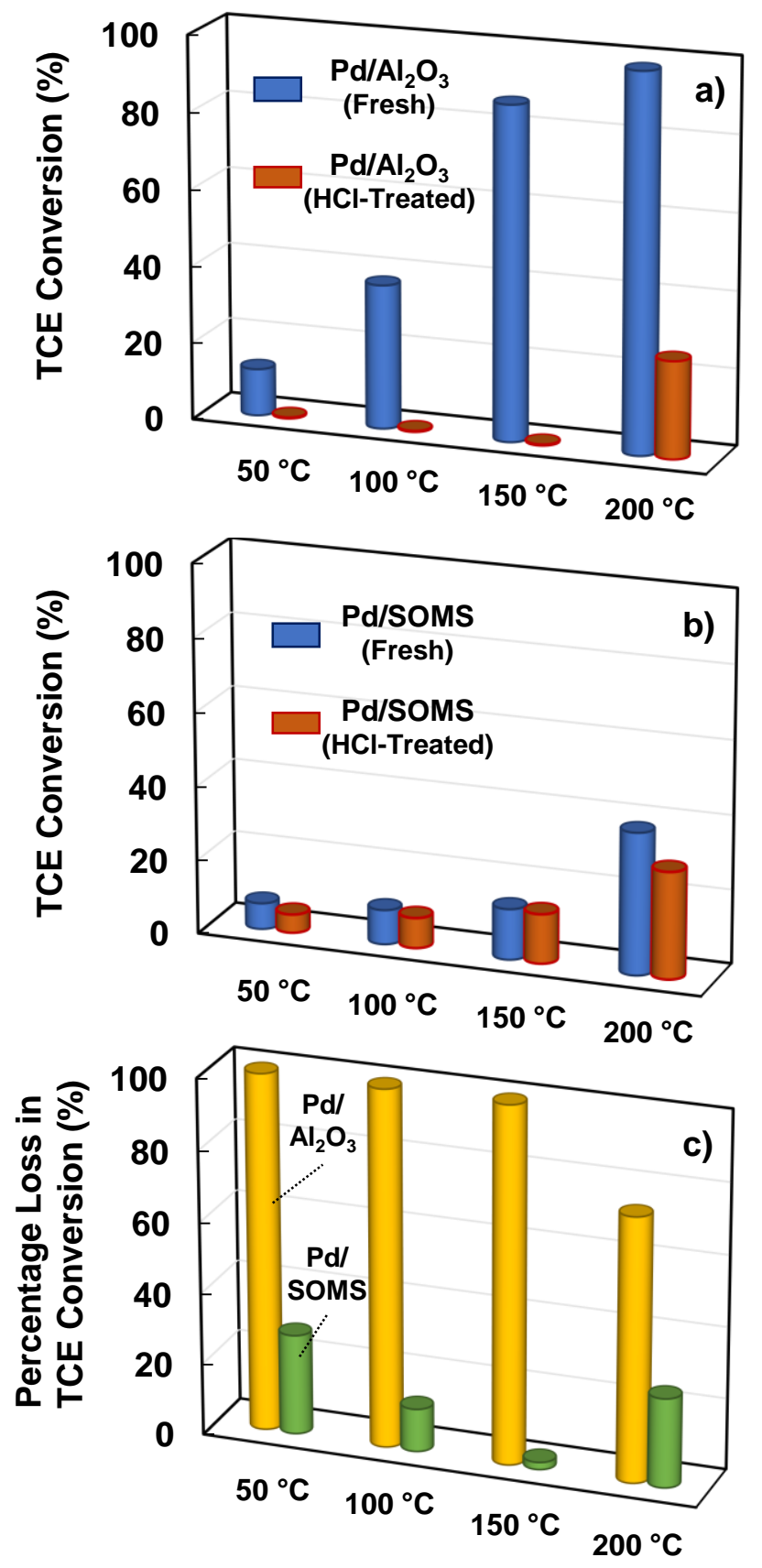

Figure 15. Catalytic activity data for fresh and $\mathrm{HCl}$-treated of a) $1 \% \mathrm{Pd} / \mathrm{Al}_{2} \mathrm{O}_{3}$ and b) $1 \% \mathrm{Pd} / \mathrm{SOMS}$ samples for HDC of TCE in continuous flow gas-phase reactor, c) percentage loss in TCE conversion due to $\mathrm{HCl}$ treatment 

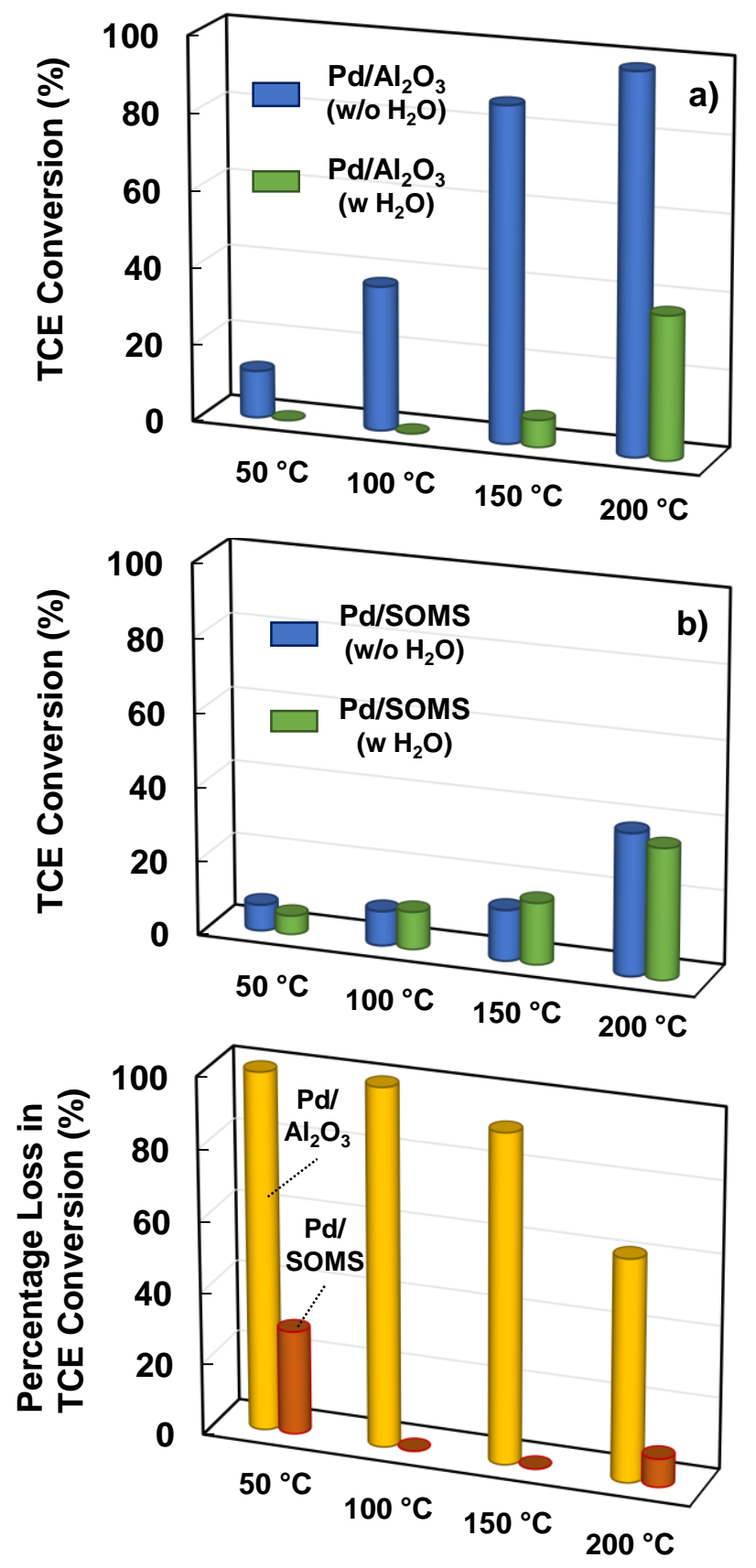

Figure 16. Catalytic activity data for a) $1 \% \mathrm{Pd} / \mathrm{Al}_{2} \mathrm{O}_{3}$ and b) $1 \% \mathrm{Pd} / \mathrm{SOMS}$ for $\mathrm{HDC}$ of TCE in the presence/absence of water in continuous flow gas-phase reactor, $\mathrm{C}$ ) percentage loss in TCE conversion due to water in the feed 
Table 1. BET Surface area, pore volume and average pore diameter of SOMS, $1 \%$ $\mathrm{Pd} / \mathrm{SOMS}$ and $1 \% \mathrm{Pd} / \mathrm{Al}_{2} \mathrm{O}_{3}$ catalysts

\begin{tabular}{cccc}
\hline & Surface Area & Pore Volume & Averaged Pore Diameter \\
\hline SOMS & $\left(\mathrm{m}^{2} / \mathrm{g}\right)$ & $\left(\mathrm{cm}^{3} / \mathrm{g}\right)$ & $(\AA)$ \\
$1 \% \mathrm{Pd} / \mathrm{SOMS}$ & 493 & 1.03 & 84 \\
$1 \% \mathrm{Pd} / \mathrm{Al}_{2} \mathrm{O}_{3}$ & 479 & 0.56 & 47 \\
\hline
\end{tabular}


Table 2. ICP-OES results showing percentages of $\mathrm{Pd}$ leached from $1 \% \mathrm{Pd} / \mathrm{Al}_{2} \mathrm{O}_{3}$ and $1 \%$ $\mathrm{Pd} / \mathrm{SOMS}$ samples after they were exposed to different concentrations of $\mathrm{HCl}$

\section{Pd leached (\%)}

\begin{tabular}{rccc}
\hline & $0 \mathrm{M} \mathrm{HCl}$ & $0.1 \mathrm{M} \mathrm{HCl}$ & $1 \mathrm{M} \mathrm{HCl}$ \\
$1 \% \mathrm{Pd} / \mathrm{Al}_{2} \mathrm{O}_{3}$ & 0 & 74.4 & $>99$ \\
$1 \% \mathrm{Pd} / \mathrm{SOMS}$ & 0 & 1.6 & 6.4 \\
\hline
\end{tabular}




\section{Graphical Abstract}

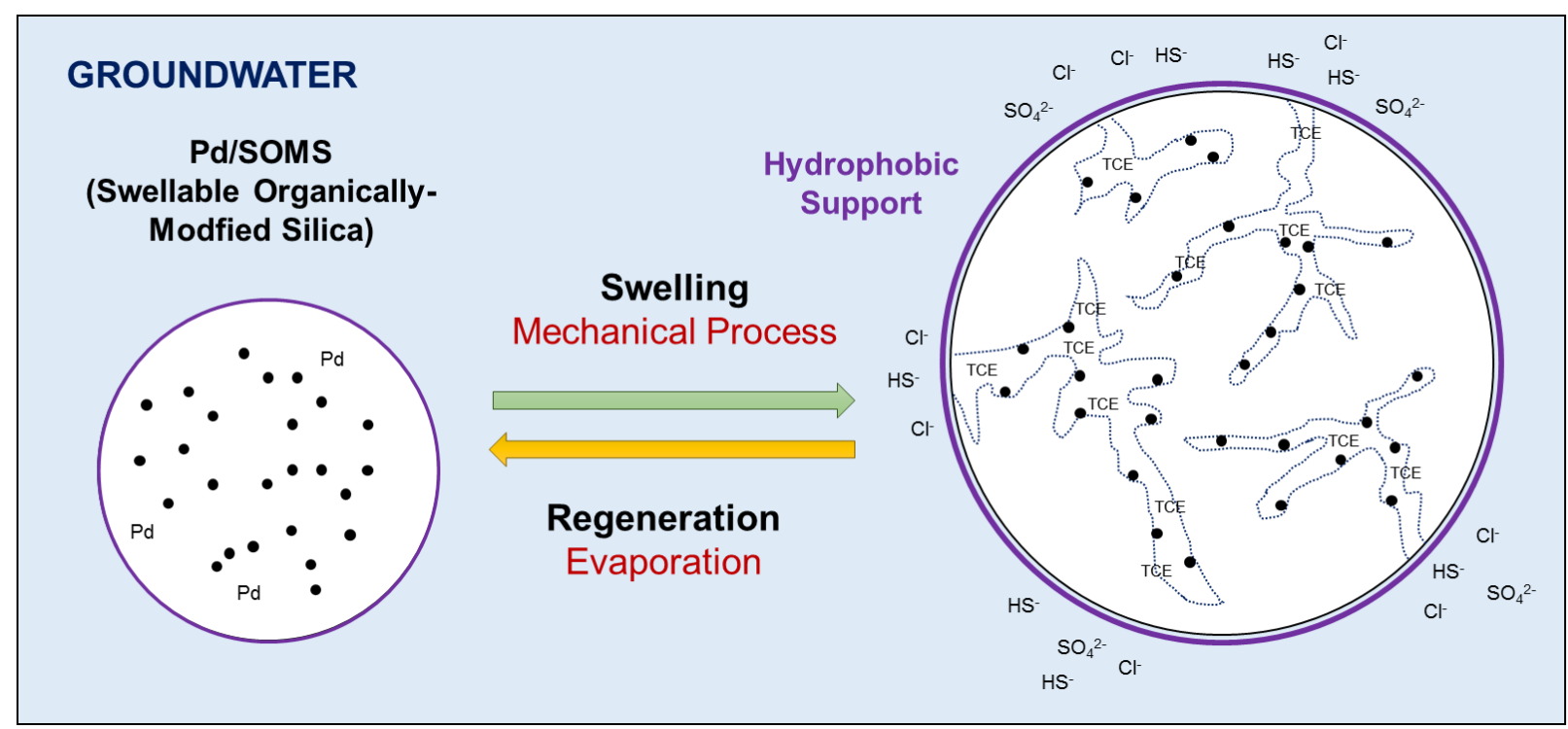

